\title{
Sensitivity of Simulated Climate to Horizontal and Vertical Resolution in the ECHAM5 Atmosphere Model
}

\author{
E. Roeckner, R. Brokopf, M. Esch, M. Giorgetta, S. Hagemann, and L. Kornblueh \\ Max Planck Institute for Meteorology, Hamburg, Germany \\ E. MANZINI \\ National Institute for Geophysics and Volcanology, Bologna, Italy \\ U. SCHLESE AND U. SCHULZWEIDA \\ Max Planck Institute for Meteorology, Hamburg, Germany
}

(Manuscript received 30 November 2004, in final form 26 July 2005)

\begin{abstract}
The most recent version of the Max Planck Institute for Meteorology atmospheric general circulation model, ECHAM5, is used to study the impact of changes in horizontal and vertical resolution on seasonal mean climate. In a series of Atmospheric Model Intercomparison Project (AMIP)-style experiments with resolutions ranging between T21L19 and T159L31, the systematic errors and convergence properties are assessed for two vertical resolutions. At low vertical resolution (L19) there is no evidence for convergence to a more realistic climate state for horizontal resolutions higher than T42. At higher vertical resolution (L31), on the other hand, the root-mean-square errors decrease monotonically with increasing horizontal resolution. Furthermore, except for T42, the L31 versions are superior to their L19 counterparts, and the improvements become more evident at increasingly higher horizontal resolutions. This applies, in particular, to the zonal mean climate state and to the stationary wave patterns in boreal winter. As in previous studies, increasing horizontal resolution leads to a warming of the troposphere, most prominently at midlatitudes, and to a poleward shift and intensification of the midlatitude westerlies. Increasing the vertical resolution has the opposite effect, almost independent of horizontal resolution. Whereas the atmosphere is colder at low and middle latitudes, it is warmer at high latitudes and close to the surface. In addition, increased vertical resolution results in a pronounced warming in the polar upper troposphere and lower stratosphere, where the cold bias is reduced by up to $50 \%$ compared to L19 simulations. Consistent with these temperature changes is a decrease and equatorward shift of the midlatitude westerlies. The substantial benefits in refining both horizontal and vertical resolution give some support to scaling arguments deduced from quasigeostrophic theory implying that horizontal and vertical resolution ought to be chosen consistently.
\end{abstract}

\section{Introduction}

Earlier studies on the sensitivity of simulated climate to spatial resolution focused essentially on two aspects:

(i) At which horizontal resolution do the numerical solutions converge?

(ii) Is there convergence toward a more realistic climate state?

Corresponding author address: Erich Roeckner, Max Planck Institute for Meteorology, Bundesstrasse 53, 20146 Hamburg, Germany.

E-mail: erich.roeckner@zmaw.de
Answering these questions is not only of scientific interest but also of practical value because it would provide a rationale for choosing a suitable resolution for the particular model. The first question has been addressed in different model configurations. Boer and Denis (1997), in experiments with prescribed idealized forcing, that is, excluding interactions between the dynamical and the physical (parameterized) part of the model, found convergence of the large-scale patterns around T63 spectral resolution. Williamson (1999) obtained more mixed results when studying features such as midlatitude transients and the local Hadley circulation. When the forcing was held fixed at $\mathrm{T} 42$ resolution, convergence of transient features was found only at 
lower wavenumbers $(\leq \mathrm{T} 42)$. There was convergence neither at the higher wavenumbers nor in the full model because of the creation of finer scales interacting with the unresolved physics through latent heat release and convection. The strength of the Hadley circulation increased systematically up to the highest horizontal resolution applied (T170). These conclusions are in contrast to those obtained from studies on the resolution dependence of the large-scale aspects of simulated climate. For example, Williamson et al. (1995) found convergence in zonal means, horizontal distributions, and transient eddy statistics in the range T42-T63. As compared to the differences T42 - T21, the differences in the horizontal distributions of wind, geopotential height, and sea level pressure were relatively small between T42 and T106. Similar conclusions were drawn by Boyle (1993), Déqué et al. (1994), and Stendel and Roeckner (1998).

Concerning the second question, numerous studies confirm the substantial reduction of systematic errors in medium-resolution models (T42, T63) compared to low-resolution models (T21, R15). This applies not only to seasonal mean climate but in particular to transient features such as eddy fluxes and processes like extratropical cyclones or blocking events. With respect to higher horizontal resolution (beyond T63) the conclusions differ between models and also depend on the climate statistics investigated. Some of the differences in model behavior at high resolution may also be attributed to the fact that in the early studies (prior to 1998) the simulation time was generally too short to obtain reliable climate statistics. Although the differences in seasonal mean climate between T42 and T106 are generally much smaller than those between T42 and $\mathrm{T} 21$, some changes can be identified that may improve or deteriorate the simulation, depending on the simulated climate in the coarser-resolution model. For example, increasing horizontal resolution from T42 to T106 increases the tropospheric temperatures, predominantly at midlatitudes, resulting in a poleward shift and intensification of the westerly jets (Boyle 1993; Déqué et al. 1994; Pope and Stratton 2002; Stendel and Roeckner 1998; Stratton 1999; Williamson et al. 1995). Whereas the warming is beneficial in models suffering from a cold bias at coarse resolution, the poleward shift and intensification of the westerlies generally increased the systematic errors in high-resolution experiments. Stratton (1999) showed that root-meansquare error (rmse) in sea level pressure increased at higher resolution, although some regional features, such as the pressure distribution over the Arctic, improved. A steady increase with resolution (T30, T42, T106) in rmse of zonal mean climate variables was also found by Stendel and Roeckner (1998). Branković and Gregory (2001) performed ensemble integrations for individual seasons at relatively high horizontal resolutions $\left(T 63, T_{L} 159\right.$, and $T_{L} 319$, where $T_{L}$ relates to a linear grid). Although some differences in the detail were found, the systematic errors were largely insensitive to the changes in horizontal resolution.

The main objective of this study is to investigate the dependence of convergence properties and systematic errors on horizontal and vertical resolution. This is assessed in a series of Atmospheric Model Intercomparison Project (AMIP)-style experiments at resolutions ranging between T21L19 and T159L31. Simulated seasonal mean climate variables are compared to those derived from the 15-yr European Centre for MediumRange Weather Forecasts (ECMWF) Re-Analysis (ERA-15; Gibson et al. 1997). Other aspects of these simulations, such as the hydrological cycle (Hagemann et al. 2006), radiative fluxes (Wild and Roeckner 2006), snow cover, and surface albedo (Roesch and Roeckner 2006) are discussed elsewhere in this issue.

The model components are briefly summarized in section 2, and the experiments are described in section 3. The results are discussed in section 4. Section 5 contains a summary of the main findings and concluding remarks.

\section{The model}

A detailed model description of ECHAM5 is given by Roeckner et al. (2003). Its main components are summarized as follows.

Like its predecessors, ECHAM5 employs a spectral dynamical core. Vorticity, divergence, temperature, and the logarithm of surface pressure are represented in the horizontal by a truncated series of spherical harmonics. The model utilizes a semi-implicit leapfrog time-differencing scheme. The growth of spurious computational modes is inhibited by a weak time filter. A hybrid sigma-pressure system is used in the vertical direction. A flux-form semi-Lagrangian scheme (Lin and Rood 1996) is used for passive tracer transport, that is, for the water components (vapor, liquid, solid) and for chemical substances (optional).

The shortwave radiation scheme (Fouquart and Bonnel 1980) uses the Eddington approximation for the integration over the zenith and azimuth angles and the delta-Eddington approximation for the reflectivity of a layer. The scheme includes Rayleigh scattering, absorption by water vapor and ozone, both varying in space and time, and $\mathrm{CO}_{2}+\mathrm{N}_{2} \mathrm{O}+\mathrm{CO}+\mathrm{CH}_{4}+\mathrm{O}_{2}$ as uniformly mixed gases. The scheme has four spectral bands, one for visible + UV range and three for the near infrared. 
Single-scattering properties of clouds have been determined on the basis of Mie calculations using idealized size distributions for both cloud droplets and ice crystals. The longwave scheme, the so-called Rapid Radiative Transfer Model (RRTM) developed by Mlawer et al. (1997), is based on the correlated-k method. Absorption coefficients were derived from the LBLRTM line-by-line model (Clough et al. 1989) and include the effect of the CKD2.2 water vapor continuum. The RRTM scheme computes fluxes in the spectral range $10-3000 \mathrm{~cm}^{-1}$. The computation is organized in 16 spectral bands and includes line absorption by $\mathrm{H}_{2} \mathrm{O}, \mathrm{CO}_{2}$, $\mathrm{O}_{3}, \mathrm{CH}_{4}, \mathrm{~N}_{2} \mathrm{O}$, CFC-11, CFC-12, and aerosols. For cloud droplets, the mass absorption coefficient is a function of the respective effective radius with coefficients independent of wavenumber as obtained from a polynomial fit to the results of Mie calculations. For ice clouds, an inverse dependency of the mass absorption coefficient on the ice crystal effective radius is assumed, and the coefficients vary with wavenumber (Ebert and Curry 1992).

The cloud scheme consists of prognostic equations for the water phases (vapor, liquid, solid), bulk cloud microphysics (Lohmann and Roeckner 1996), and a statistical cloud cover scheme with prognostic equations for the distribution moments (Tompkins 2002). The microphysics scheme includes phase changes between the water components and precipitation processes (autoconversion, accretion, aggregation). Moreover, evaporation of rain and melting of snow are considered, as well as sedimentation of cloud ice. A mass flux scheme is employed for shallow, midlevel, and deep convection (Tiedtke 1989) with modifications for deep convection according to Nordeng (1994). The scheme is based on steady-state equations for mass, heat, moisture, cloud water, and momentum for an ensemble of updrafts and downdrafts, including turbulent and organized entrainment and detrainment. Cloud water detrainment in the upper part of the convective updrafts is used as a source term in the stratiform cloud water equations. For deep convection, an adjustment-type closure is used with convective activity expressed in terms of convective available potential energy.

The subgrid-scale orography parameterization developed by Lott and Miller (1997) takes into account two main mechanisms of interaction between subgrid-scale orography and the atmospheric flow: 1) momentum transfer from the earth to the atmosphere accomplished by orographic gravity waves and 2) the drag exerted by the subgrid-scale mountain when the airflow is blocked at low levels. Momentum flux deposition from a gravity wave spectrum is used only in the middle-atmosphere
(MA) version of ECHAM5 [for details see Roeckner et al. (2003)].

Horizontal diffusion is expressed in the form of a scale-selective hyper-Laplacian applied to vorticity, divergence, and temperature. Free parameters are the order of scheme and the diffusion coefficient or, alternatively, the $e$-folding damping time of the highest resolvable wavenumber. The turbulent surface fluxes for momentum, heat, and moisture are obtained from bulk transfer relationships involving the difference of the respective model variable (wind components, potential temperature, humidity) between the surface and the lowest model level (about $30 \mathrm{~m}$ above ground), the wind velocity at that level, and the transfer coefficients. The latter are obtained from Monin-Obukhov similarity theory. Over land, transpiration is limited by stomatal resistance, whereas bare soil evaporation is limited by the availability of soil water. Eddy viscosity and diffusivity are parameterized in terms of turbulent kinetic energy and length scales involving the mixing length and stability functions for momentum and heat, respectively.

The land surface temperature is obtained from the surface energy balance equation using an implicit coupling scheme that is unconditionally stable and allows synchronous calculation of the respective prognostic variables and surface fluxes. Four reservoirs are defined for the water components, that is, snow at the canopy, snow at the surface, liquid water at the canopy, and soil water. Surface runoff and drainage depend on the heterogeneous distribution of field capacities within a grid cell. A simple scheme is used for calculating the water temperature, ice thickness, and ice temperature of lakes. The albedo of snow and ice depends on surface temperature. Over snow-covered land, the mean albedo of a grid cell depends on fractional forest area, leaf area index, bare soil albedo, snow albedo, fractional snow cover at both ground and canopy, and slope of terrain. Land surface parameters were compiled from a global distribution of major ecosystem types (Hagemann 2002) made available by the U.S. Geological Survey.

\section{Resolution experiments}

A series of AMIP-style experiments (Gates et al. 1999) was performed using observed monthly sea surface temperatures and sea ice cover for the time period 1978-99. The output of the first year of each experiment was omitted. A seasonal climatology (DJF, MAM, JJA, SON) was constructed from the $15-y r$ period 1979-93 and compared with the respective ERA15 dataset (Gibson et al. 1997). For estimating the rep- 
TABLE 1. Model resolutions and global annual mean top-of-atmosphere radiation budget. The radiation time step is $2 \mathrm{~h}$ in each experiment. The simulated 15-yr mean radiative fluxes $\left(\mathrm{W} \mathrm{m}^{-2}\right)$ are clear-sky and all-sky absorbed shortwave radiation (ASR), outgoing longwave (OLR), net radiation (ASR - OLR), and shortwave (SW) and longwave (LW) cloud-radiative forcing. Observational estimates are from $2 \mathrm{yr}$ of ERBE data (Hartmann 1993) and $5 \mathrm{yr}$ of ISCCP data (Raschke et al. 2005). The uncertainty in the global mean fluxes for both ERBE and ISCCP is about $\pm 5 \mathrm{~W} \mathrm{~m}^{-2}$.

\begin{tabular}{lccccccccc}
\hline \hline Resolution & $\begin{array}{c}\text { Grid } \\
\left(^{\circ}\right)\end{array}$ & $\begin{array}{c}\Delta t \\
(\mathrm{~min})\end{array}$ & $\begin{array}{c}\text { ASR } \\
(\text { clear })\end{array}$ & $\begin{array}{c}\text { OLR } \\
(\text { clear })\end{array}$ & $\begin{array}{c}\text { SW } \\
(\text { cloud })\end{array}$ & $\begin{array}{c}\text { LW } \\
(\text { cloud })\end{array}$ & $\begin{array}{c}\text { ASR } \\
(\text { all })\end{array}$ & $\begin{array}{c}\text { OLR } \\
(\text { all })\end{array}$ & $\begin{array}{c}\text { ASR }- \text { OLR } \\
(\text { all })\end{array}$ \\
\hline T21 L19 & 5.62 & 40 & 286.8 & 258.8 & -53.6 & 27.0 & 233.1 & 231.8 & 1.3 \\
T31 L19 & 3.75 & 40 & 286.6 & 259.1 & -53.8 & 27.3 & 233.8 & 231.9 & 1.9 \\
T42 L19 & 2.81 & 30 & 286.7 & 259.6 & -53.0 & 27.2 & 233.7 & 232.4 & 1.3 \\
T63 L19 & 1.87 & 20 & 286.7 & 260.1 & -53.3 & 27.2 & 233.4 & 232.9 & 0.5 \\
T85 L19 & 1.41 & 15 & 286.8 & 260.2 & -53.6 & 27.4 & 233.2 & 232.8 & 0.4 \\
T106 L19 & 1.12 & 12 & 286.8 & 260.2 & -53.7 & 27.3 & 233.1 & 232.9 & 0.3 \\
T42 L31 & 2.81 & 20 & 286.7 & 260.5 & -53.2 & 28.3 & 233.5 & 232.2 & 1.3 \\
T63 L31 & 1.87 & 12 & 286.8 & 261.3 & -53.0 & 28.3 & 233.7 & 233.1 & 0.6 \\
T85 L31 & 1.41 & 8 & 286.8 & 261.8 & -52.8 & 27.8 & 234.0 & 234.0 & 0.0 \\
T106 L31 & 1.12 & 6 & 286.8 & 262.2 & -51.5 & 27.1 & 235.3 & 235.1 & 0.2 \\
T159 L31 & 0.75 & 4 & 286.7 & 262.4 & -50.6 & 25.9 & 236.2 & 236.5 & -0.3 \\
ERBE & & & 288 & 264 & -48 & 30 & 240 & 234 & 6 \\
ISCCP & & & 286 & 258 & -50 & 25 & 236 & 233 & 3 \\
\hline
\end{tabular}

resentativeness of ERA-15, the 1979-93 subset of ERA-40 (Uppala et al. 2005) was used in addition. Except for model tuning (see below), the experiments differ only with respect to horizontal and/or vertical resolution. A list of the resolution experiments together with the respective top-of-atmosphere radiative fluxes is presented in Table 1. The L19 vertical grid is identical to that used in previous ECHAM models, and the L31 grid is identical to that used in the ERA-15 model (see Roeckner et al. 2003, their Table 2.2). In all experiments the top level is placed at $10 \mathrm{hPa}$. The top three and bottom three levels are identical in both grids. In the L19 (L31) model the geometrical grid spacing in the free troposphere increases gradually with height from about $1 \mathrm{~km}(500 \mathrm{~m})$ in the lower troposphere, to $1.5 \mathrm{~km}$ $(750 \mathrm{~m})$ in the middle troposphere, and $2 \mathrm{~km}(1 \mathrm{~km})$ around the tropopause.

Except for a few parameter changes, the physical package remains identical. Some of the parameter changes are directly linked to resolution changes as, for instance, the damping time of the highest resolvable wavenumber in the horizontal diffusion scheme, the subgrid-scale parameters in the orographic drag scheme, or the adjustment time scale utilized in the penetrative convection parameterization. Other parameters had to be tuned in order to approximately satisfy the global mean radiation balance at the top of the atmosphere (see Table 1). A similar strategy was applied by Williamson et al. (1995), Stendel and Roeckner (1998), and Pope and Stratton (2002). As apparent from Table 1, there is no resolution dependence of the shortwave clear-sky fluxes but some effect on the clear-sky OLR, with systematically larger fluxes, up to
$3.6 \mathrm{~W} \mathrm{~m}^{-2}$, at higher horizontal and especially vertical resolution. Because of inaccuracies of radiometers, sampling errors, and other factors, the net clear-sky fluxes (ASR - OLR) clear $>0$ in the satellite data are not compensated by the net cloud-radiative forcing $(\mathrm{SW}+\mathrm{LW})_{\text {cloud }}<0$, so that the net radiation budget (ASR - OLR) all is positive $\left[6 \mathrm{~W} \mathrm{~m}^{-2}\right.$ for the Earth Radiation Budget Experiment (ERBE) and $3 \mathrm{~W} \mathrm{~m}^{-2}$ for the International Satellite Cloud Climatology $\mathrm{Ex}$ periment (ISCCP)]. In the model simulations the net radiation budget is closer to zero. This has been achieved by modifying free parameters in the cloud and convection schemes that affect the precipitation efficiency and, hence, cloud cover, cloud water content, and cloud radiative forcing. At all model resolutions, the simulated clear-sky fluxes as well as the cloud radiative forcings are within the range of the observational uncertainties of about $\pm 5 \mathrm{~W} \mathrm{~m}^{-2}$.

\section{Results and discussion}

\section{a. Root-mean-square errors}

The rmses were calculated from the differences between simulated seasonal climatologies and the respective ERA-15 and ERA-40 data for the period 1979-93. This includes basic climate variables like temperature, geopotential height, and zonal wind in the upper troposphere $(200 \mathrm{hPa})$, middle troposphere $(500 \mathrm{hPa})$, and lower troposphere $(850 \mathrm{hPa})$, and mean sea level pressure. Table 2 shows the respective rmse with respect to ERA-15 averaged over all four seasons. In most cases the errors decrease with increasing horizontal resolution. However, there are a few exceptions, most notably 
TABLE 2. Rmses with respect to ERA-15, and rms differences (rmsds) between ERA-15 and ERA-40, averaged over all four seasons, for temperature $(T)$, geopotential height $(Z)$, and zonal wind $(U)$ at pressure levels 200,500 , and $850 \mathrm{hPa}$, respectively, and for mean sea level pressure (SLP). Rmse and rmsd are given in units of ${ }^{\circ} \mathrm{C}$ for $T$, dam for $Z, \mathrm{hPa}$ for mean SLP, and $\mathrm{m} \mathrm{s}^{-1}$ for $U$. Increasing errors with increasing horizontal resolution are set in boldface.

\begin{tabular}{lcccccccccc}
\hline \hline Variable & T200 & T500 & T850 & Z200 & Z500 & Z850 & SLP & U200 & U500 & U850 \\
\hline T21L19 & 6.20 & 2.00 & 1.89 & 8.10 & 6.46 & 5.05 & 6.31 & 7.77 & 4.82 & 3.40 \\
T31L19 & 5.54 & 1.42 & $\mathbf{2 . 1 4}$ & 7.13 & 3.58 & 2.68 & 3.55 & 5.97 & 3.12 & 2.40 \\
T42L19 & 5.12 & 1.00 & $\mathbf{2 . 0 2}$ & 7.04 & 3.25 & 1.93 & 2.55 & 4.48 & 2.37 & 1.92 \\
T63L19 & 4.74 & 0.96 & 1.88 & $\mathbf{7 . 9 1}$ & $\mathbf{3 . 7 3}$ & 1.76 & 2.32 & 3.57 & 2.16 & 1.73 \\
T85L19 & 4.64 & $\mathbf{1 . 1 4}$ & 1.80 & $\mathbf{8 . 8 0}$ & $\mathbf{4 . 1 3}$ & $\mathbf{1 . 7 8}$ & 2.32 & $\mathbf{3 . 6 4}$ & $\mathbf{2 . 2 6}$ & 1.71 \\
T106L19 & 4.51 & $\mathbf{1 . 2 2}$ & 1.75 & $\mathbf{9 . 0 2}$ & $\mathbf{4 . 1 8}$ & 1.70 & 2.23 & 3.41 & 2.15 \\
T42L31 & 5.10 & 1.15 & 1.81 & 6.33 & 2.63 & 2.13 & 2.81 & 5.60 & 2.57 & 1.60 \\
T63L31 & 4.41 & 0.84 & 1.65 & 4.40 & 2.16 & 1.65 & 2.17 & 4.50 & 2.02 & 1.51 \\
T85L31 & 4.11 & 0.78 & 1.57 & 3.69 & 2.07 & 1.48 & 1.95 & 3.92 & 1.91 & 1.38 \\
T106L31 & 3.91 & $\mathbf{0 . 7 9}$ & 1.57 & 3.31 & 2.07 & 1.40 & 1.86 & 3.44 & 1.74 & 1.26 \\
T159L31 & 3.22 & $\mathbf{0 . 8 0}$ & $\mathbf{1 . 5 9}$ & 2.91 & 1.98 & 1.30 & 1.75 & 2.84 & 1.64 & 1.13 \\
ERA-40 & 0.68 & 0.40 & 1.08 & 0.83 & 0.67 & 0.56 & 1.25 & 0.73 & 0.85 & 0.61 \\
\hline
\end{tabular}

Z200 and Z500 in the L19 simulations: Whereas these errors decrease between $\mathrm{T} 21$ and T42, they increase steadily between T42 and T106. In the L31 simulations there is virtually no evidence for such an anomalous behavior. With the exception of a small increase of the T500 and T850 errors in T106L31 and T159L31, there is a monotonic decrease of rmse with increasing horizontal resolution. As to be expected, the rms differences between ERA-15 and ERA-40 are systematically smaller than the rmse errors with respect to ERA-15 or to ERA-40 (not shown). This is more evident in the upper troposphere than in the lower troposphere. As evident from Table 3, which shows the rmse ratios of L31 and L19 simulations with respect to both ERA-15 and ERA-40, the L31 simulations are generally closer to the reanalyses than their L19 counterparts. A notable exception is the T42 model, where a better vertical resolution does not improve the simulation. In the T63, T85, and T106 simulations the beneficial effect of higher vertical resolution is particularly evident for Z200 and Z500, but improvements are found for the other variables and levels as well. The only exception is the zonal wind at $200 \mathrm{hPa}$, which is too strong at low latitudes in the L31 simulations (see Figs. 7 and 10).

Based on the numbers shown in Table 2, a simple ranking scheme was designed by calculating the ratio of the respective rmse and those from the T21L19 simulation, and averaging these normalized errors over all variables and levels. This was done separately for the total fields (Fig. 1a), for the zonal means (Fig. 1b), and also for the stationary wave components (Fig. 1c). In the L19 simulations (left-hand columns), in agreement with most earlier studies (see section 1), there is no evidence for an overall rmse decrease in the total and zonal mean fields for resolutions higher than T42, but there are significant improvements from T21 to T42 and a general improvement up to T106 in the stationary wave components (Fig. 1c). However, this slight improvement in the stationary waves hardly affects the resolution dependence of the total rmse because stationary wave amplitudes are relatively small except in boreal winter. Increased vertical resolution (from L19 to L31) is beneficial in two aspects. First, the errors are smaller than their L19 counterparts (except for T42) by up to $17 \%$ for T106. Second, the errors decrease monotonically with increasing horizontal resolution up to the highest horizontal resolution applied in this study (T159). The improvements in the L31 simulations compared to L19 are more pronounced in the zonal means (up to $20 \%$ decrease in normalized error; see Fig. 1b)

TABLE 3. Impact of vertical resolution on systematic errors. Shown is the ratio of seasonal mean rmse (L31/L19) with respect to ERA-15 and ERA-40 (parentheses) for different horizontal resolutions. Rmse ratios $>1$ (bold) indicate larger errors in the L31 simulations than in the L19 simulations.

\begin{tabular}{lcccccccccc}
\hline \hline & T200 & T500 & T850 & Z200 & Z500 & Z850 & SLP & U200 & U500 & U850 \\
\hline T42 & $1.00(\mathbf{1 . 0 2})$ & $\mathbf{1 . 1 5}(\mathbf{1 . 2 3})$ & $0.90(0.88)$ & $0.90(0.97)$ & $0.81(0.85)$ & $\mathbf{1 . 1 0}(\mathbf{1 . 0 6})$ & $\mathbf{1 . 1 0}(\mathbf{1 . 0 5})$ & $\mathbf{1 . 2 5}(\mathbf{1 . 2 4})$ & $\mathbf{1 . 0 8}(\mathbf{1 . 1 1})$ & $1.00(\mathbf{1 . 0 1})$ \\
$\mathrm{T} 63$ & $0.93(0.95)$ & $0.88(0.91)$ & $0.88(0.90)$ & $0.56(0.58)$ & $0.58(0.63)$ & $0.94(0.85)$ & $0.94(0.81)$ & $\mathbf{1 . 2 6}(\mathbf{1 . 2 4})$ & $0.94(0.97)$ & $0.87(0.89)$ \\
T85 & $0.89(0.90)$ & $0.68(0.72)$ & $0.87(0.89)$ & $0.42(0.42)$ & $0.50(0.55)$ & $0.83(0.73)$ & $0.84(0.70)$ & $\mathbf{1 . 0 8}(\mathbf{1 . 0 3})$ & $0.85(0.85)$ & $0.81(0.81)$ \\
T106 & $0.87(0.88)$ & $0.65(0.67)$ & $0.90(0.93)$ & $0.37(0.37)$ & $0.49(0.54)$ & $0.82(0.74)$ & $0.83(0.70)$ & $\mathbf{1 . 0 1}(0.98)$ & $0.81(0.83)$ & $0.79(0.81)$ \\
\hline
\end{tabular}



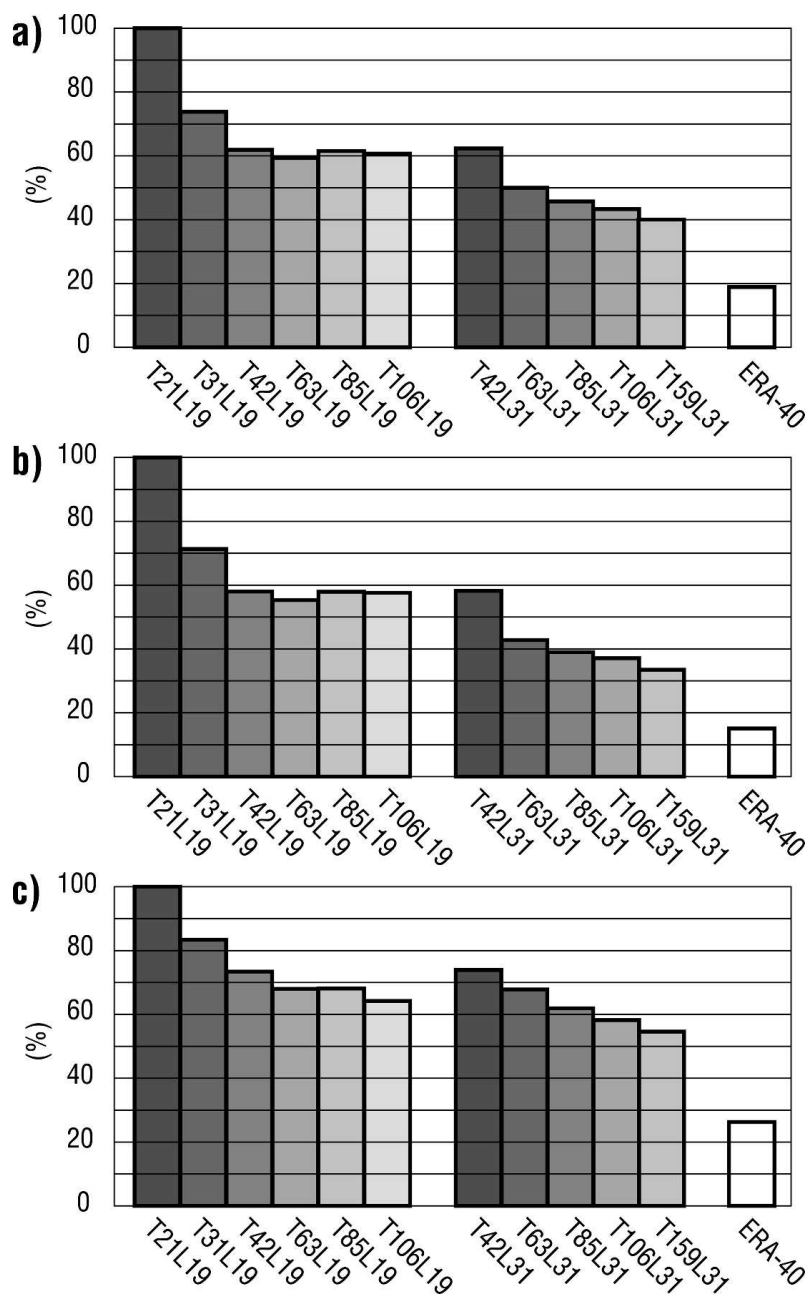

FIG. 1. Resolution dependence of rmses with respect to ERA15. Shown are normalized overall rmse (see text) of (a) total fields, (b) zonal means, and (c) stationary waves. Rms differences between ERA-15 and ERA-40 are shown in the right-hand columns. All values are expressed as percentages of the respective T21L19 rmse. than in the stationary waves (up to $6 \%$ decrease; see Fig. 1c). Although the rms differences between ERA15 and ERA-40 (right-hand columns) approach some $50 \%$ of the T159L31 rmse, the resolution dependence of the systematic errors shown in Tables 2 and 3 and in Fig. 1 is independent of the verifying datasets used in this study (ERA-15 and ERA-40).

These results show that, in the L19 simulations, there is no evidence for convergence to a more realistic climate state at horizontal resolutions $>$ T42. In the L31 simulations, on the other hand, the rmse decreases monotonically with increasing horizontal resolution (T42 to T159). Furthermore, except for T42 horizontal resolution, the L31 versions are superior to their L19 counterparts, and the improvements become more evident at increasingly higher horizontal resolutions. The substantial benefits in refining horizontal and vertical resolution at the same time give some support to scaling arguments deduced from quasigeostrophic theory (Lindzen and Fox-Rabinovitz 1989) implying that horizontal and vertical resolution ought to be chosen consistently. For quasigeostrophic flows the Rossby ratio of horizontal and vertical scales is given by $L / H=N / f_{0}$ $\approx 100$, where $N$ is the Brunt-Väisälä frequency and $f_{0}$ a characteristic Coriolis parameter. Lindzen and FoxRabinovitz (1989) also showed that the vertical resolution requirement is even more demanding for internal gravity waves. Table 4 compares the vertical grid spacing at $500 \mathrm{hPa}$ in the L19 and L31 models with those derived from the consistency relationship at $45^{\circ}$ for two choices of $\mathrm{N}$ corresponding to oscillation periods of 5 and $8 \mathrm{~min}$, respectively. According to Table 4, L19 vertical resolution is adequate for T31 and T42, whereas L31 is adequate for T63 and T85. Even higher vertical resolution would be required for T106 and T159. It has to be pointed out, however, that this analysis can only provide a rough first hint for the proper choice of the

TABLE 4. Vertical grid spacing $(\Delta z)$ for L19 and L31 models compared to that derived from the Rossby ratio of horizontal and vertical scales, $\Delta x / \Delta z=\left(N / f_{0}\right)$, where $f_{0}$ is the characteristic Coriolis parameter and $N$ is the Brunt-Väisälä frequency. In this example, $f_{0}\left(45^{\circ}\right)$ $=10^{-4} \mathrm{~s}^{-1}, N_{1}=2 \pi / 300 \mathrm{~s}$, and $N_{2}=2 \pi / 480 \mathrm{~s}$, respectively (Lindzen and Fox-Rabinovitz 1989). The "consistency" between horizontal and vertical resolution for quasigeostrophic flow at $45^{\circ}$ is set in boldface.

\begin{tabular}{cccccc}
\hline \hline $\begin{array}{c}\text { Spectral } \\
\text { resolution }\end{array}$ & $\begin{array}{c}\Delta x \text { at } \\
45^{\circ}(\mathrm{km})\end{array}$ & $\Delta z\left(N_{1}\right)(\mathrm{m})$ & $\Delta z\left(N_{2}\right)(\mathrm{m})$ & $\begin{array}{c}\Delta z(\mathrm{~L} 19) \text { at } \\
500 \mathrm{hPa}(\mathrm{m})\end{array}$ & $\begin{array}{c}\Delta z(\mathrm{~L} 31) \text { at } \\
500 \mathrm{hPa}(\mathrm{m})\end{array}$ \\
\hline T21 & 442 & 2110 & 3377 & 1500 & 750 \\
T31 & 295 & 1408 & 2254 & $\mathbf{1 5 0 0}$ & 750 \\
T42 & 221 & 1055 & 1688 & $\mathbf{1 5 0 0}$ & 750 \\
T63 & 147 & 702 & 1123 & 1500 & $\mathbf{7 5 0}$ \\
T85 & 111 & 530 & 848 & 1500 & 7500 \\
T106 & 88 & 420 & 451 & 1500 & 750 \\
T159 & 59 & 282 & &
\end{tabular}



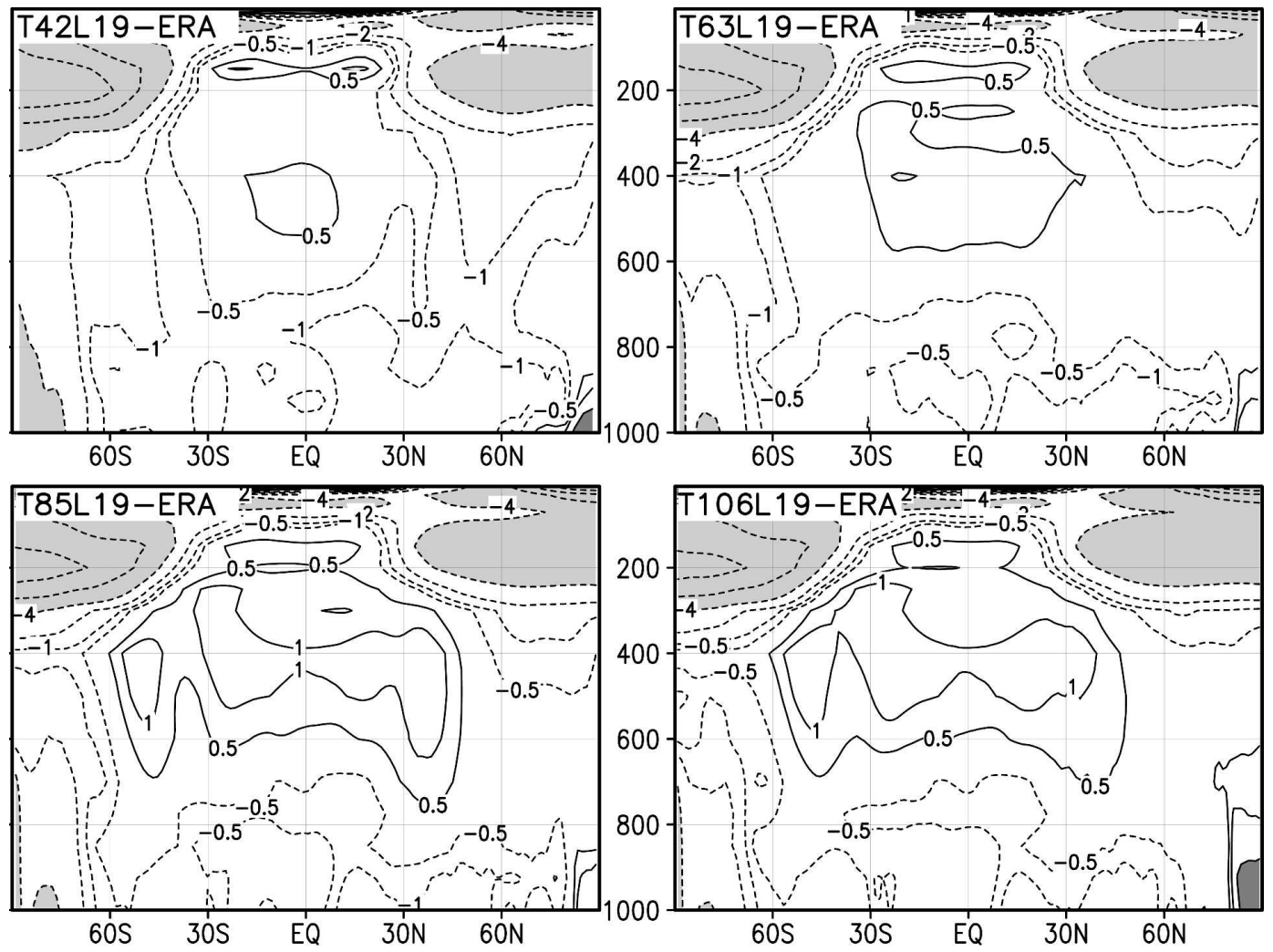

FIG. 2. Latitude-height (pressure in $\mathrm{hPa}$ ) distributions of zonal mean temperature errors (DJF) in L19 simulations. Contours are $\pm 0.5^{\circ}, 1^{\circ}, 2^{\circ}, 4^{\circ}, 8^{\circ}$, and $12^{\circ} \mathrm{C}$. Light shading is for differences $<-4^{\circ} \mathrm{C}$, dark shading for differences $>2^{\circ} \mathrm{C}$.

vertical model resolution, because neither $f_{0}$ nor $N$ are constants, and $\Delta z$ varies with height (with $\Delta z$ shown in Table 4 representing approximately a free-tropospheric mean).

\section{b. Zonal means}

Latitude-height cross sections of DJF zonal mean temperature errors in L19 simulations are shown in Fig. 2. As in virtually all earlier studies, higher horizontal resolution results in a gradual tropospheric warming. In some regions this extra warming is beneficial because a cold bias at lower resolution is diminished as, for example, the cold bias in the lower troposphere and at high latitudes in the T42 simulation. In other regions the systematic errors increase because a warm bias already present at lower resolution is enhanced. This is particularly evident in the middle troposphere (see also Table 2) at low and middle latitudes. The warm bias increases steadily between T42 and T85 with some indication of convergence at this resolution though not in all regional details. In the respective L31 simulations (Fig. 3) an overall cold bias prevails. As in L19, there is a gradual warming with increasing horizontal resolution in much of the troposphere. The difference pattern (L31 - L19) in zonal mean DJF temperature (Fig. 4) is largely independent of horizontal resolution. The most notable features are cooling of the middle and upper troposphere at low and middle latitudes and highlatitude warming, most pronounced between 200 and $100 \mathrm{hPa}$. Almost all of these changes are beneficial (see also Table 2) and remarkably similar to those found by Pope et al. (2001) in Hadley Centre Atmospheric Model (HadAM3) simulations.

The evolution of the warm bias in the L19 simulations is even more evident during JJA, with values exceeding $2^{\circ} \mathrm{C}$ at T85 and T106 resolution in parts of the summer hemisphere (not shown). In the L31 simulations, a warm bias during JJA is also evolving in parts of the troposphere, but this is smaller by typically $50 \%$ compared to L19. The impact of increased vertical resolution on the zonal mean temperature bias is similar to that in DJF (see Fig. 4) and beneficial throughout the domain: Compared to L19 there is less warming at low and middle latitudes, less cooling at high southern latitudes, and, in particular, a substantial reduction of the cold bias in the polar upper troposphere and lower 

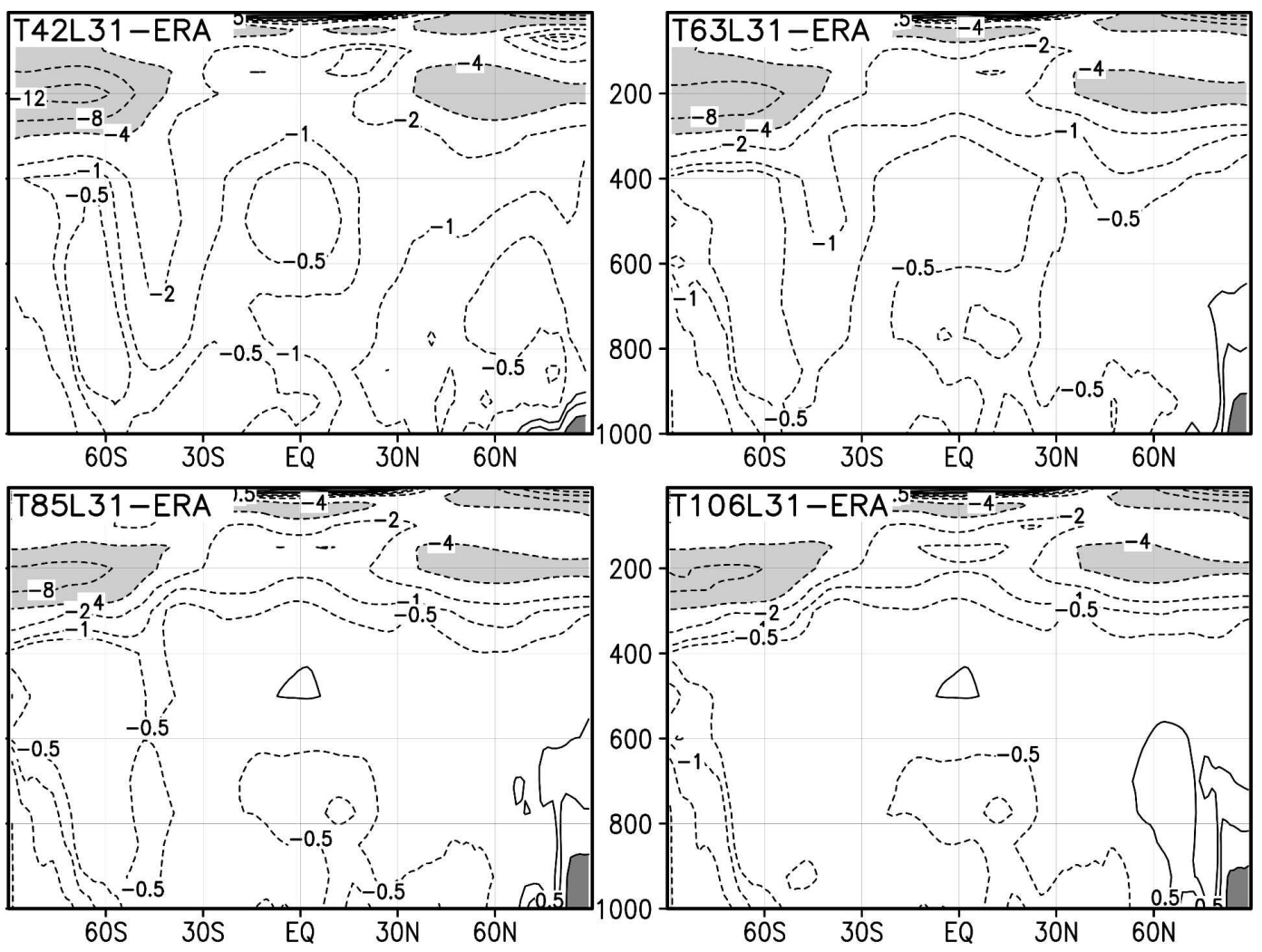

FIG. 3. As in Fig. 2, but for L31 simulations.
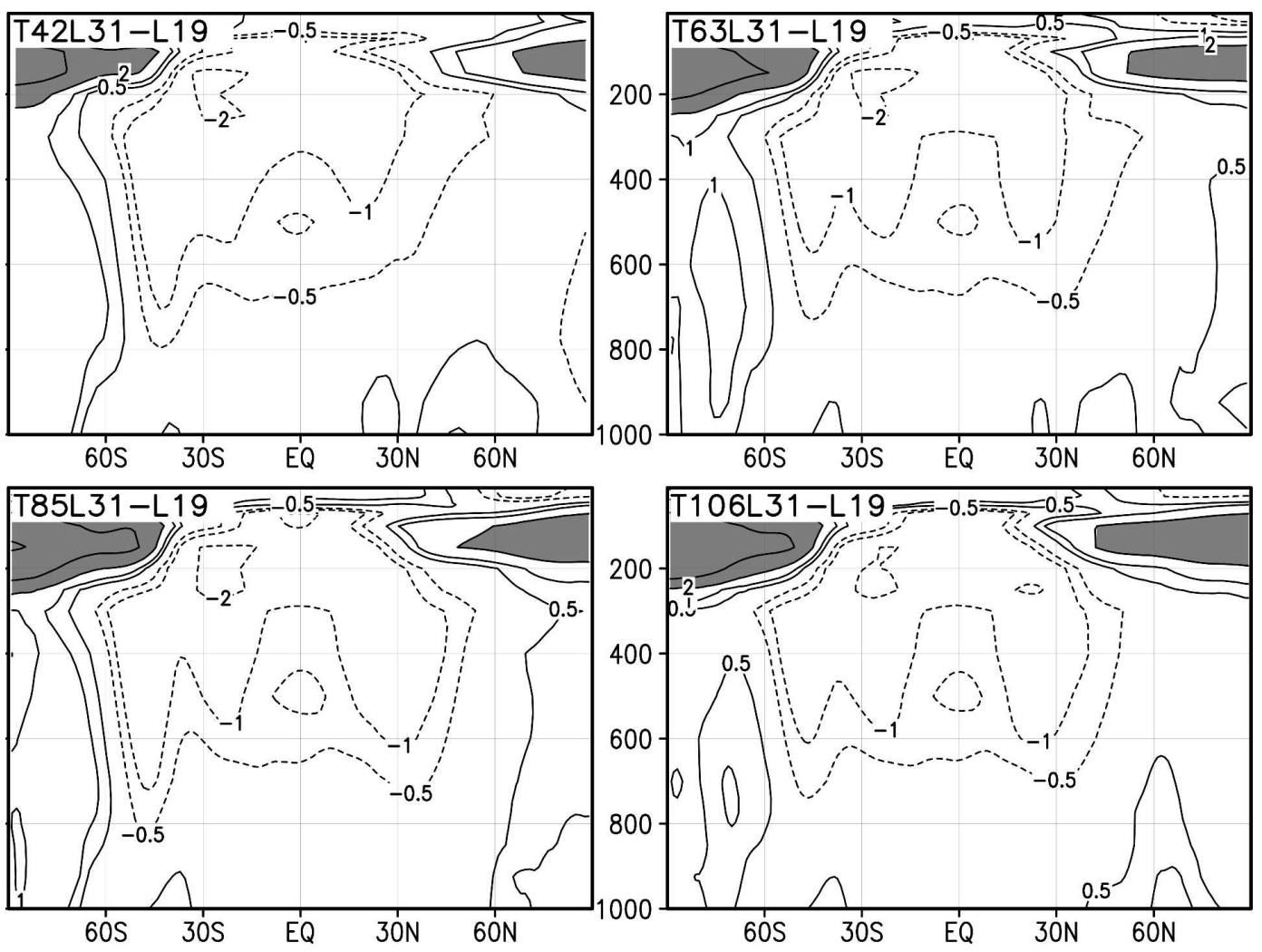

FIG. 4. As in Fig. 2, but for model differences L31 - L19. 
DJF
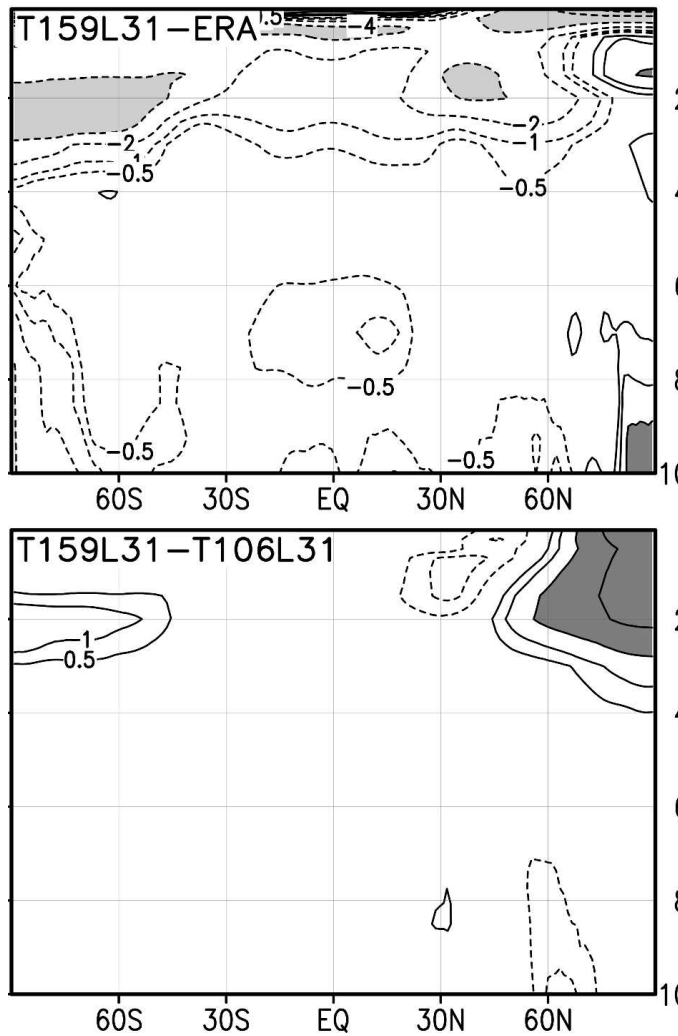

JJA
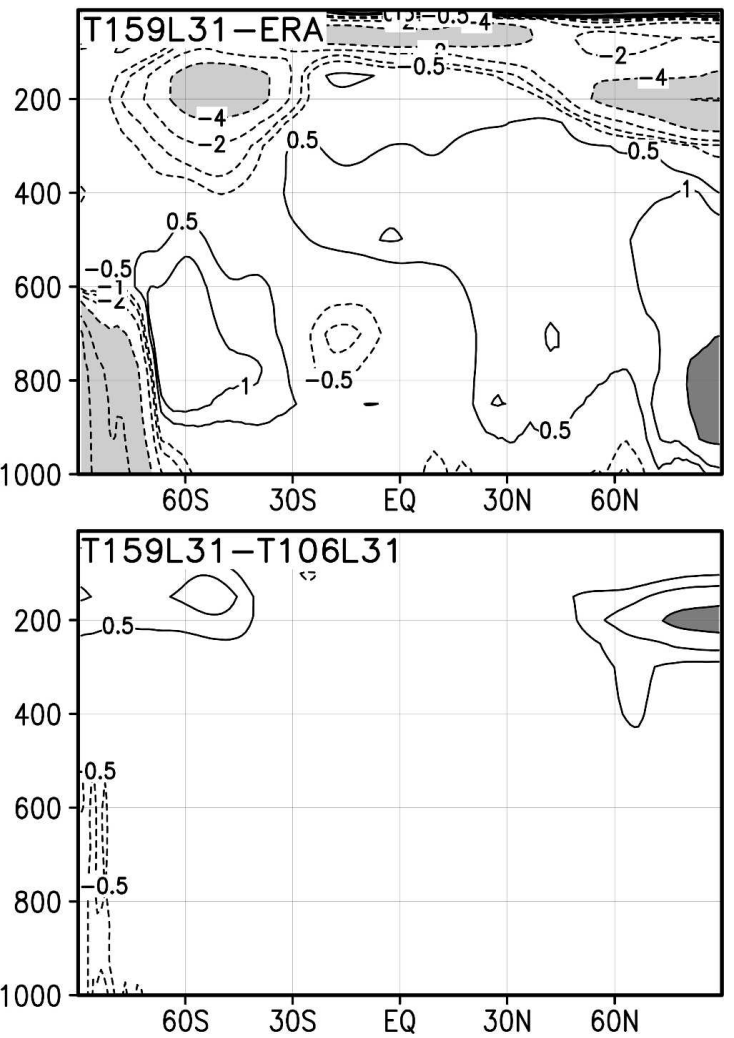

FIG. 5. Latitude-height (pressure in hPa) distributions of DJF and JJA temperature errors in (top) the T159L31 simulation and (bottom) the model differences T159L31 - T106L31. Contours are $\pm 0.5^{\circ}, 1^{\circ}, 2^{\circ}, 4^{\circ}, 8^{\circ}$, and $12^{\circ} \mathrm{C}$. Light shading is for differences $<-4^{\circ} \mathrm{C}$, dark shading for differences $>2^{\circ} \mathrm{C}$.

stratosphere. In T159L31 (Fig. 5) the error patterns are generally similar to those of T106L31 (see Fig. 3). In much of the troposphere the differences (T159 - T106) are smaller than $0.5 \mathrm{~K}$. Larger changes are found in the polar upper troposphere and lower stratosphere, where the T159 temperatures are systematically higher compared to T106. Noteworthy is the DJF warm bias over the North Pole (relative to ERA-15), which is in contrast to the respective error patterns at lower horizontal resolution (see Fig. 3). This sign reversal is probably caused by an overly strong gravity wave drag (no attempt was made to optimize the parameters at this resolution). In the respective summer hemisphere the gravity wave drag is relatively unimportant. Therefore, the decrease of the cold polar bias around $200 \mathrm{hPa}$ in the T159L31 simulation compared to T106L31 (more than $1 \mathrm{~K}$ in DJF over the South Pole and more than 2 $\mathrm{K}$ in JJA over the North Pole) is more likely due to the increase in horizontal resolution (see also the decrease in rmse at this level: Table 2, first column).

Figure 6 shows the impact of horizontal resolution on DJF zonal wind errors in the L19 simulations. From
T42 to T85 there is a gradual evolution of a pattern found in many earlier resolution studies (see section 1), that is, an unrealistic poleward shift of the midlatitude westerlies throughout the troposphere, especially in the Southern Hemisphere. However, there is no evidence for a further deterioration at T106 resolution. In the Northern Hemisphere, an improvement is found compared to T85, and the T106 pattern is actually similar to that of T63. A beneficial effect of increased horizontal resolution can be identified in the middle and upper tropical troposphere. Here, the westerly wind bias evident at T42 resolution is gradually diminished at higher resolution (see Table 2).

As in the L19 simulations, increasing horizontal resolution leads to a poleward shift of the midlatitude westerlies in the L31 simulations as well. However, unlike L19, increasing horizontal resolution is beneficial at L31 vertical resolution (Fig. 7). For example, in the T42L31 simulation, the error between $30^{\circ}$ and $70^{\circ} \mathrm{S}$ reflects an equatorward shift and weakening of the climatological westerlies. As horizontal resolution is increased, this error becomes less pronounced until it 

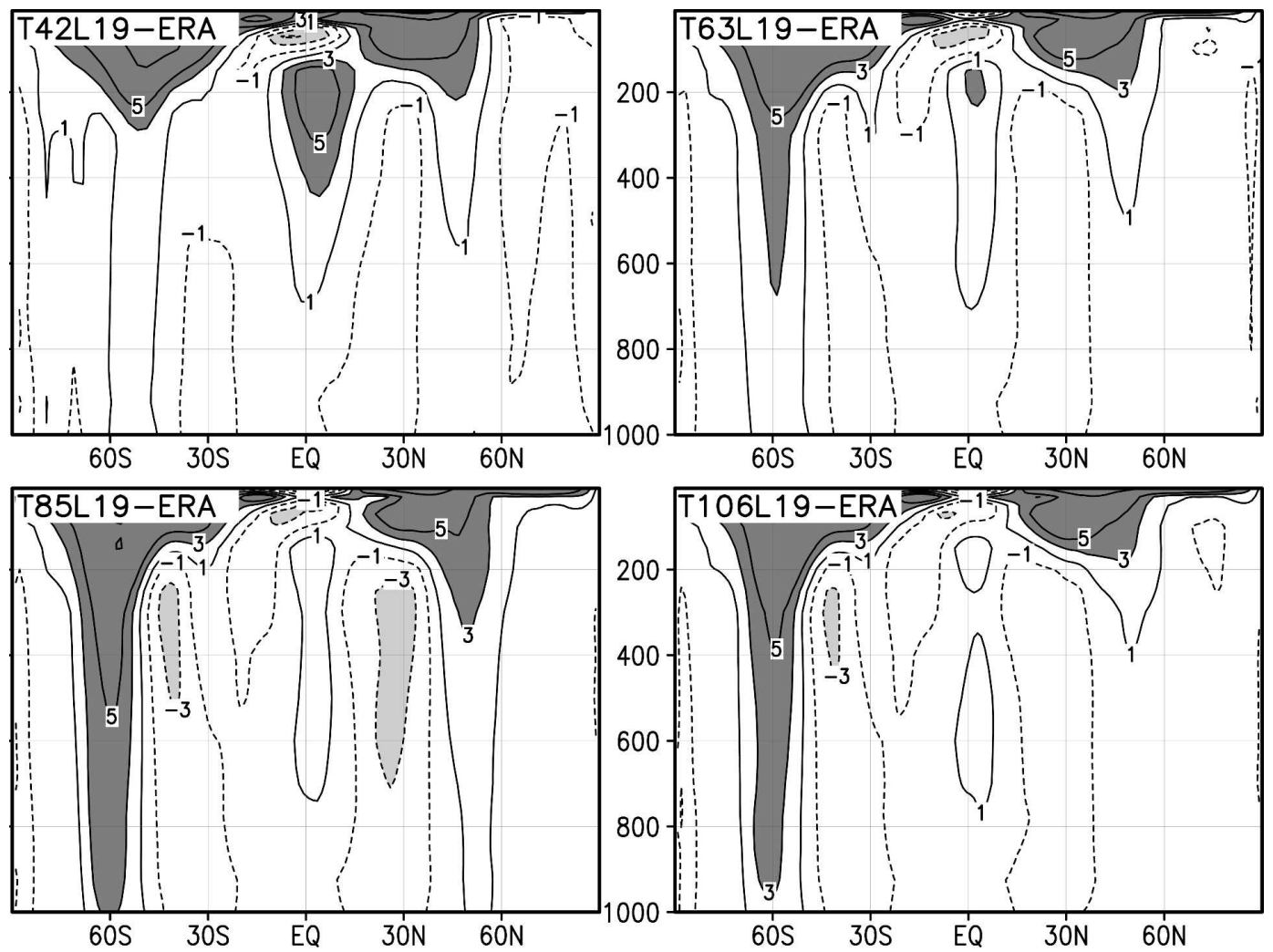

FIG. 6. Latitude-height (pressure in $\mathrm{hPa}$ ) distributions of zonal mean zonal wind errors (DJF) in L19 simulations. Contours are $\pm 1,3,5$, and $10 \mathrm{~m} \mathrm{~s}^{-1}$. Light shading is for differences $<-3 \mathrm{~m} \mathrm{~s}^{-1}$, dark shading for differences $>3 \mathrm{~m} \mathrm{~s}^{-1}$.

practically disappears at T106 resolution. Higher vertical resolution tends to reduce the midlatitude westerly wind bias above $200 \mathrm{hPa}$, whereas the uppertropospheric westerly bias in the Tropics is more pronounced than in the L19 simulations (see Table 2). As for temperature, the impact of increased vertical resolution on zonal wind (Fig. 8) is largely independent of horizontal resolution. Consistent with the respective temperature changes (see Fig. 4), the midlatitude westerlies move equatorward and weaken. This is more pronounced in the Southern Hemisphere than in the Northern Hemisphere. Easterly components, relative to L19, are simulated throughout the stratosphere, whereas westerlies occur in the upper tropical troposphere. These changes are again very similar to those found by Pope et al. (2001). Most of the changes (L31L19) are beneficial at sufficiently high horizontal resolution ( $\geq \mathrm{T} 63)$.

Figure 9 shows JJA errors in zonal mean zonal wind in the L19 simulations. The Northern Hemisphere westerlies are always too strong, and the impact of increasing horizontal resolution is only modest. In the T42 simulation, the Southern Hemisphere westerlies are too weak and shifted equatorward. As the resolution is increased, the errors become smaller and almost vanish at T85 and T106 resolution. Also, as in DJF, the westerly wind bias in the middle and upper tropical troposphere decreases with increasing horizontal resolution. At higher vertical resolution (Fig. 10) an overall improvement compared to the L19 simulations is not so clear. Whereas the westerly bias centered around $50^{\circ} \mathrm{N}$ is reduced, the easterly bias around $60^{\circ} \mathrm{S}$ is indicative for decreased westerlies at the poleward flank of the jet. Although the easterly bias is less pronounced at higher horizontal resolution (T85, T106) it is larger than in the respective L19 simulations. Also, as in DJF, the westerly wind bias in the middle and upper tropical troposphere is larger than in the L19 simulations. On the other hand, the midlatitude westerly bias above 200 $\mathrm{hPa}$ is reduced in the $\mathrm{L} 31$ simulations. The similar patterns at higher resolution suggest convergence around $\mathrm{T} 85$.

The differences in JJA zonal wind between the L31 and L19 simulations is shown in Fig. 11. Apart from details, the impact of horizontal resolution is relatively small, and the basic pattern is established already in the 

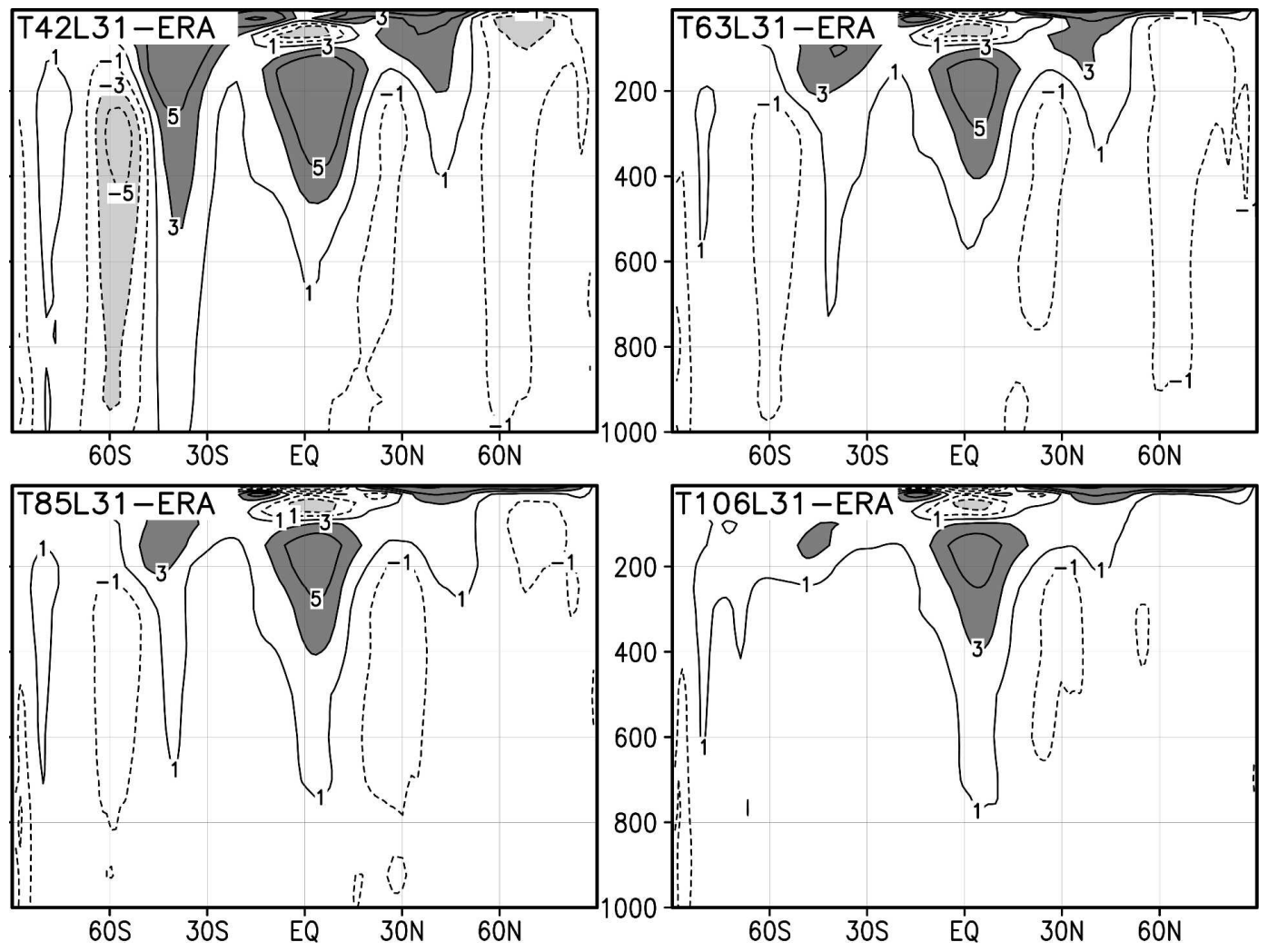

FIG. 7. As in Fig. 6, but for L31 simulations.
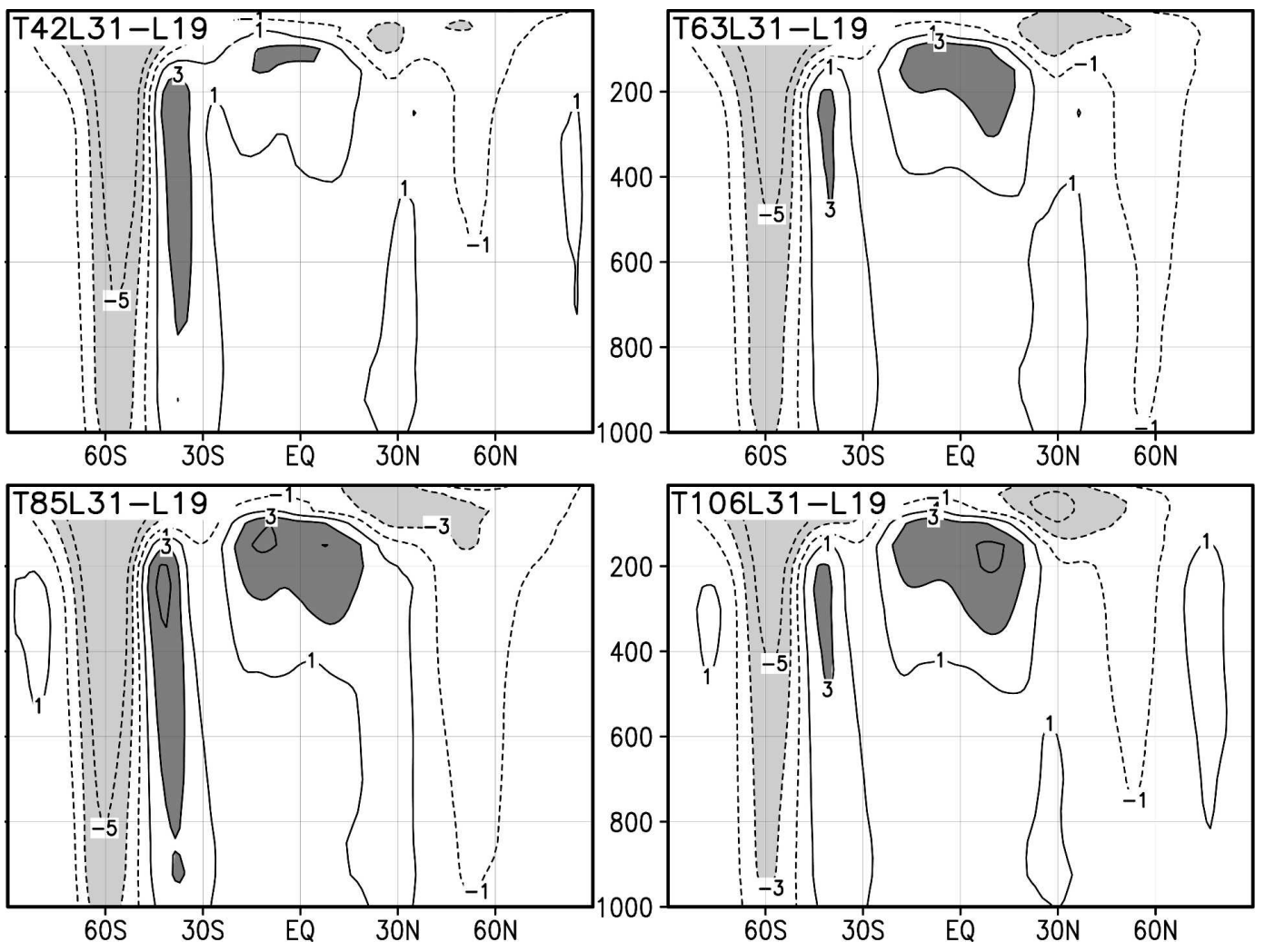

FIG. 8. As in Fig. 6, but for differences L31 - L19. 

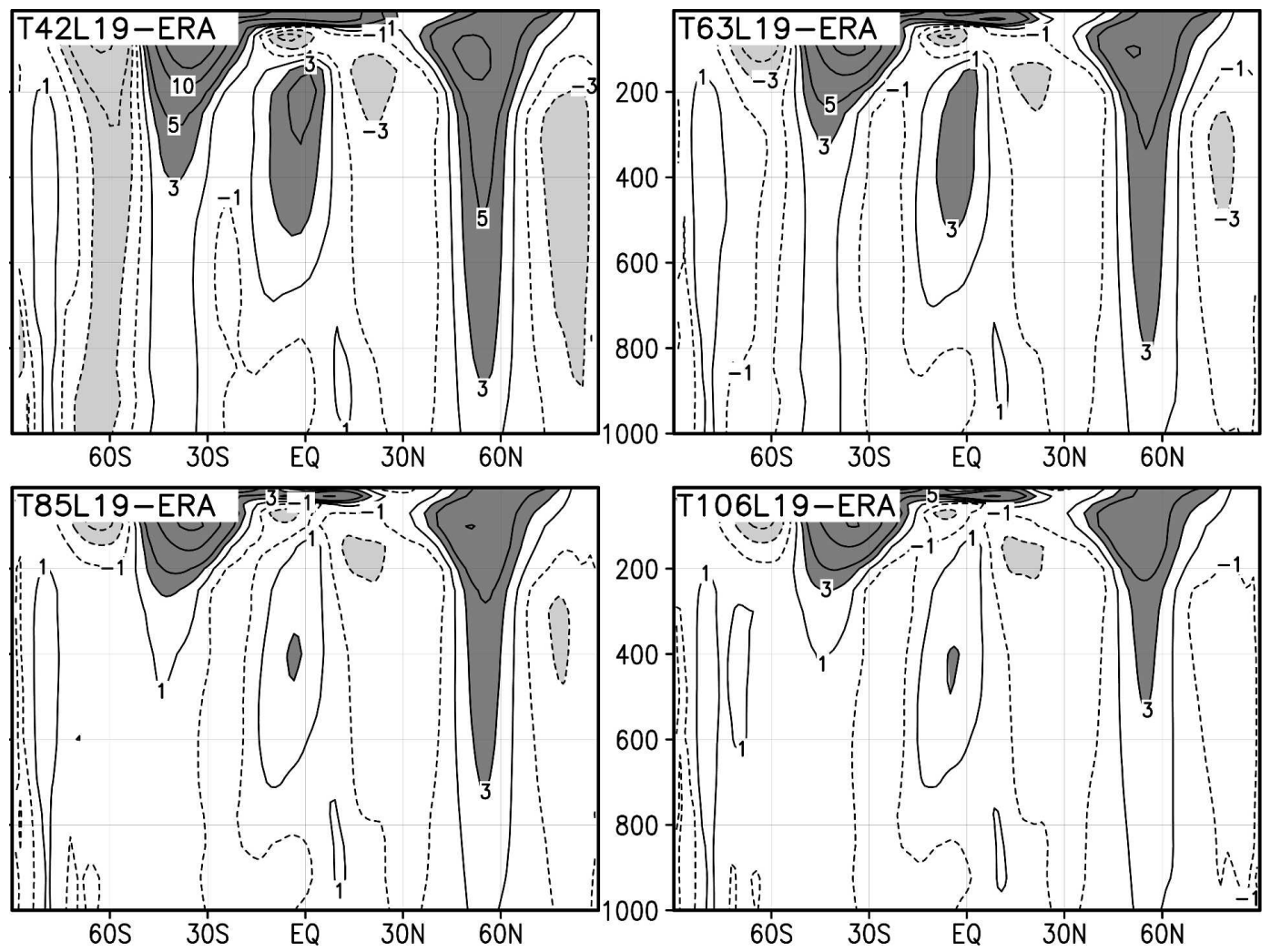

FIG. 9. Latitude-height (pressure in hPa) distributions of zonal mean zonal wind errors (JJA) in L19 simulations. Contours are $\pm 1,3,5$, and $10 \mathrm{~m} \mathrm{~s}^{-1}$. Light shading is for differences $<-3 \mathrm{~m} \mathrm{~s}^{-1}$, dark shading for differences $>3 \mathrm{~m} \mathrm{~s}^{-1}$.

T42 simulations. There are noticeable modifications at T63 resolution in the Southern Hemisphere but hardly any changes for resolutions $>$ T63. As in DJF (Fig. 8), easterly components, relative to L19, are simulated in the stratosphere and on the poleward flanks of the tropospheric westerlies. On the other hand, westerlies are found at lower latitudes with maxima of up to $5 \mathrm{~m} \mathrm{~s}^{-1}$ below the tropical tropopause, enhancing the westerly wind bias relative to L19 (see Tables 2 and 3). In T159L31 (Fig. 12), most of the errors seen in T106L31 can be found as well. An exception is the weakening of the DJF polar night jet, relative to both ERA-15 and T06L31, which is consistent with the overly strong gravity wave drag (as discussed earlier).

Errors in zonal mean $500-\mathrm{hPa}$ geopotential height and zonal mean sea level pressure are shown in Fig. 13 for DJF and JJA, respectively. In general, increased vertical resolution, from L19 to L31, has a substantially bigger impact than the increase in horizontal resolution from T63 to T106. In the L19 simulations a positive bias in Z500 is found throughout the domain, with the exception of high southern latitudes during DJF: The positive (negative) biases in both Z500 and SLP be- tween $30^{\circ}$ and $60^{\circ} \mathrm{S}\left(60^{\circ}\right.$ and $\left.90^{\circ} \mathrm{S}\right)$ is consistent with the westerly wind bias in the L19 simulations centered around $60^{\circ} \mathrm{S}$ (see Fig. 6). During JJA, the improvements in the L31 simulations are less systematic, and some deterioration, compared to L19, is found at high southern latitudes: The positive biases in both Z500 and SLP poleward of about $50^{\circ} \mathrm{S}$ are consistent with the easterly wind biases in the L31 simulations centered around $60^{\circ} \mathrm{S}$ (see Fig. 10). In MAM the errors in the L31 simulation are relatively small and similar to DJF, whereas the SON errors resemble those of JJA (not shown).

\section{c. Geographic distributions}

Figure 14 shows the geographic distribution of the observed (ERA-15) DJF sea level pressure distribution together with the errors in the T106L19 and T106L31 simulations, respectively. The substantial improvements at L31 noticed already in the zonal means (see Fig. 13) are obviously not due to error compensation along latitudes but can be found in almost every grid point (see also Tables 2 and 3). Virtually all of the mean climatological features are better captured with respect 

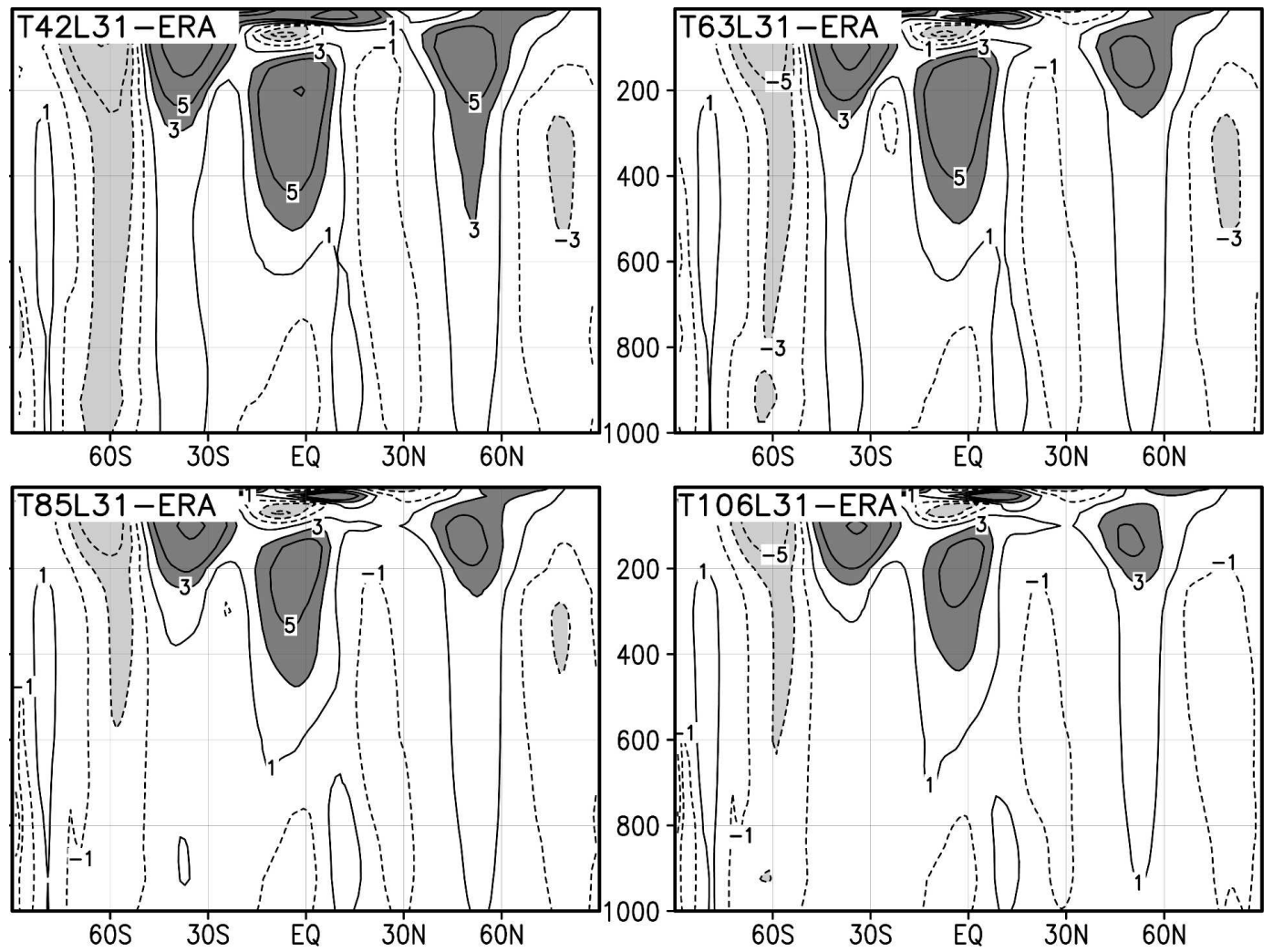

FIG. 10. As in Fig. 9, but for L31 simulations.
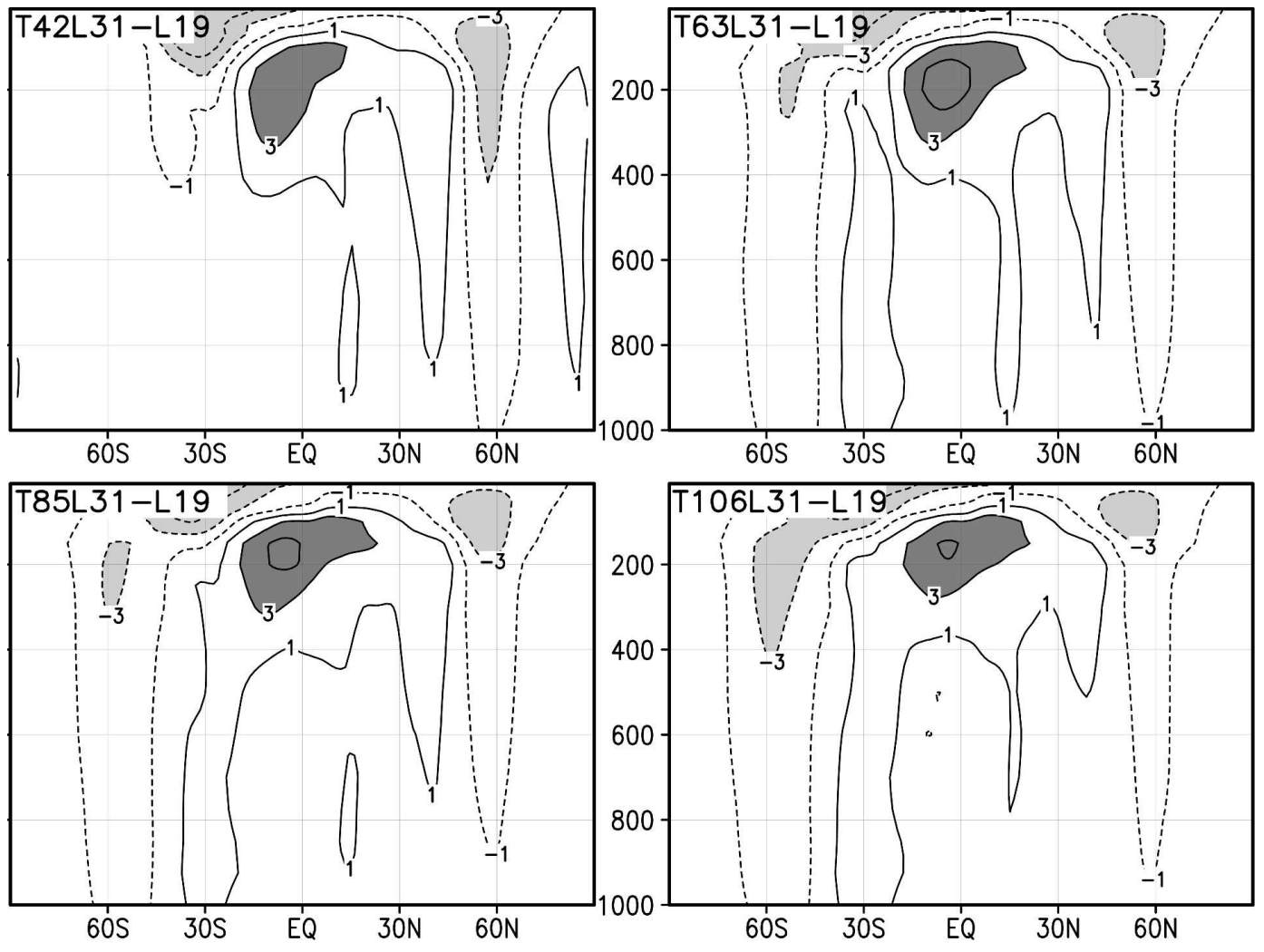

Fig. 11. As in Fig. 9, but for differences L31 - L19. 
DJF
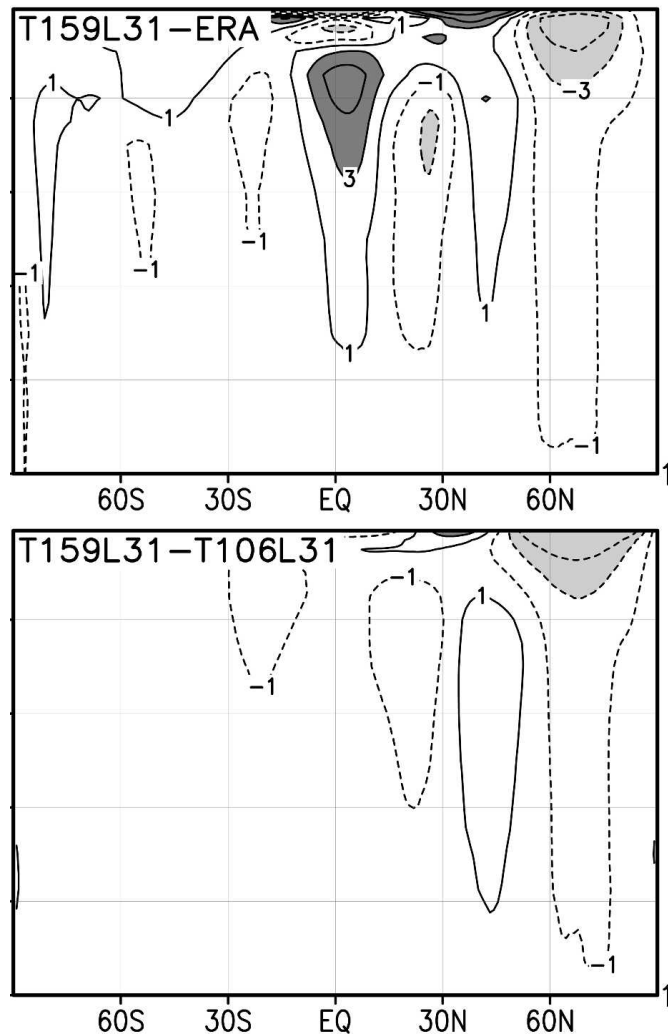

JJA
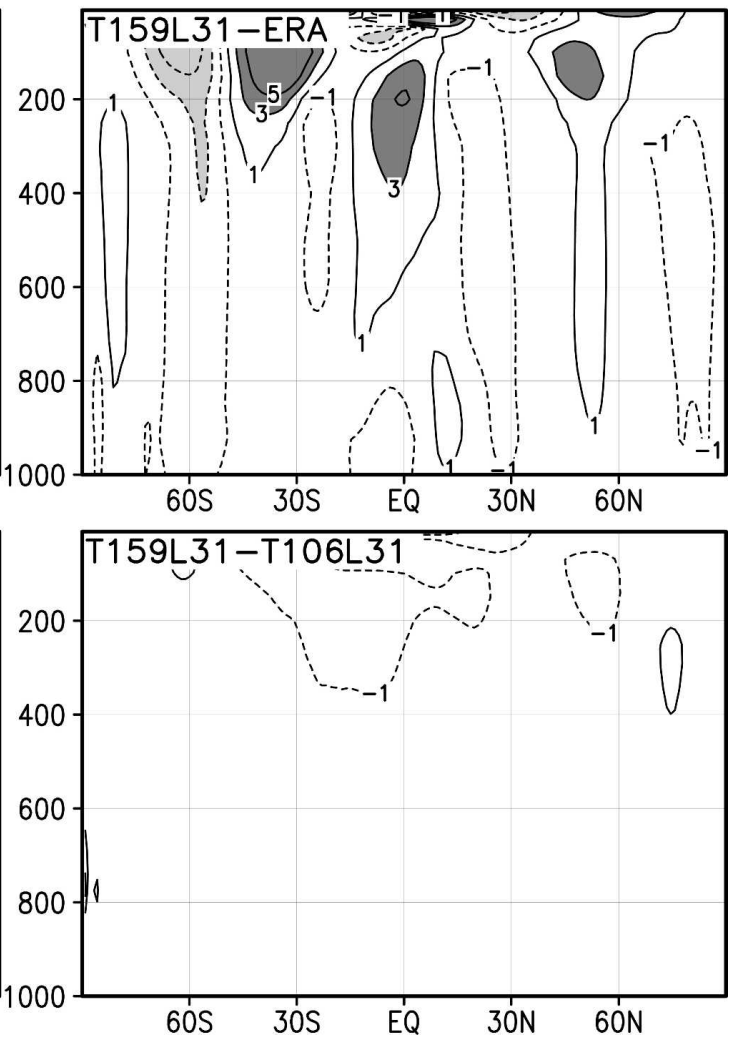

FIG. 12. Latitude-height (pressure in hPa) distributions of DJF and JJA zonal wind errors in the (top) T159L31 simulation and (bottom) model differences T159L31 - T106L31. Contours are $\pm 1,3,5$, and $10 \mathrm{~m} \mathrm{~s}^{-1}$. Light shading is for differences $<-3 \mathrm{~m} \mathrm{~s}^{-1}$, dark shading for differences $>3 \mathrm{~m} \mathrm{~s}^{-1}$.

to position and strength in the L31 simulation like, for example, the Icelandic and Aleutian lows, the trough around Antarctica, the Siberian high, and also the anticyclones over the subtropical oceans. In JJA (Fig. 15) the improvements in the L31 simulation are evident as well, though they are smaller than in DJF. For example, the high pressure bias over the North Pacific in L19 is significantly reduced in L31. Also, the low pressure bias at high northern latitudes $(<3 \mathrm{hPa}$ in L19) can hardly be found in the L31 simulation. In the Southern Hemisphere, the error patterns are different, but there is no improvement in the L31 simulation (see Fig. 13).

Stationary waves, triggered predominantly by orography and land-sea contrast but also influenced by transient eddies and dependent on the mean zonal flow, are important features of the Northern Hemisphere climate in winter. Figure 16 shows a comparison between model simulations and ERA-15 of stationary wave patterns in 500-hPa geopotential height during DJF in the Northern Hemisphere. In the T106L19 simulation the ridge over the east Atlantic and Europe is well captured. In the other regions the simulation shows defi- ciencies that are typical for all L19 simulations. The amplitude of the west Pacific trough is well captured, but it is not far enough extended to the east. Most obvious is the underestimation of the ridge over the Rocky Mountains and the underestimation of the trough over the eastern part of North America. In the L31 simulations the stationary waves are captured more realistically. This applies to all features discussed above, except for the East Atlantic Ridge, which is somewhat too high compared to ERA-15. The superiority of the L31 simulations is clearly evident in the respective error patterns shown in Fig. 17. As for the variables discussed earlier, the impact of increased vertical resolution is larger than that of increased horizontal resolution. Some of the errors in the L19 simulations are no longer visible in the L31 simulations, like, for example, the east Pacific-Rocky Mountains anomalies, whereas some other features persist, such as the slightly too high values in the center of the west Pacific and North American troughs and the low-pressure bias over parts of the North Atlantic and northern Europe. In general, however, the amplitude of these error patterns 

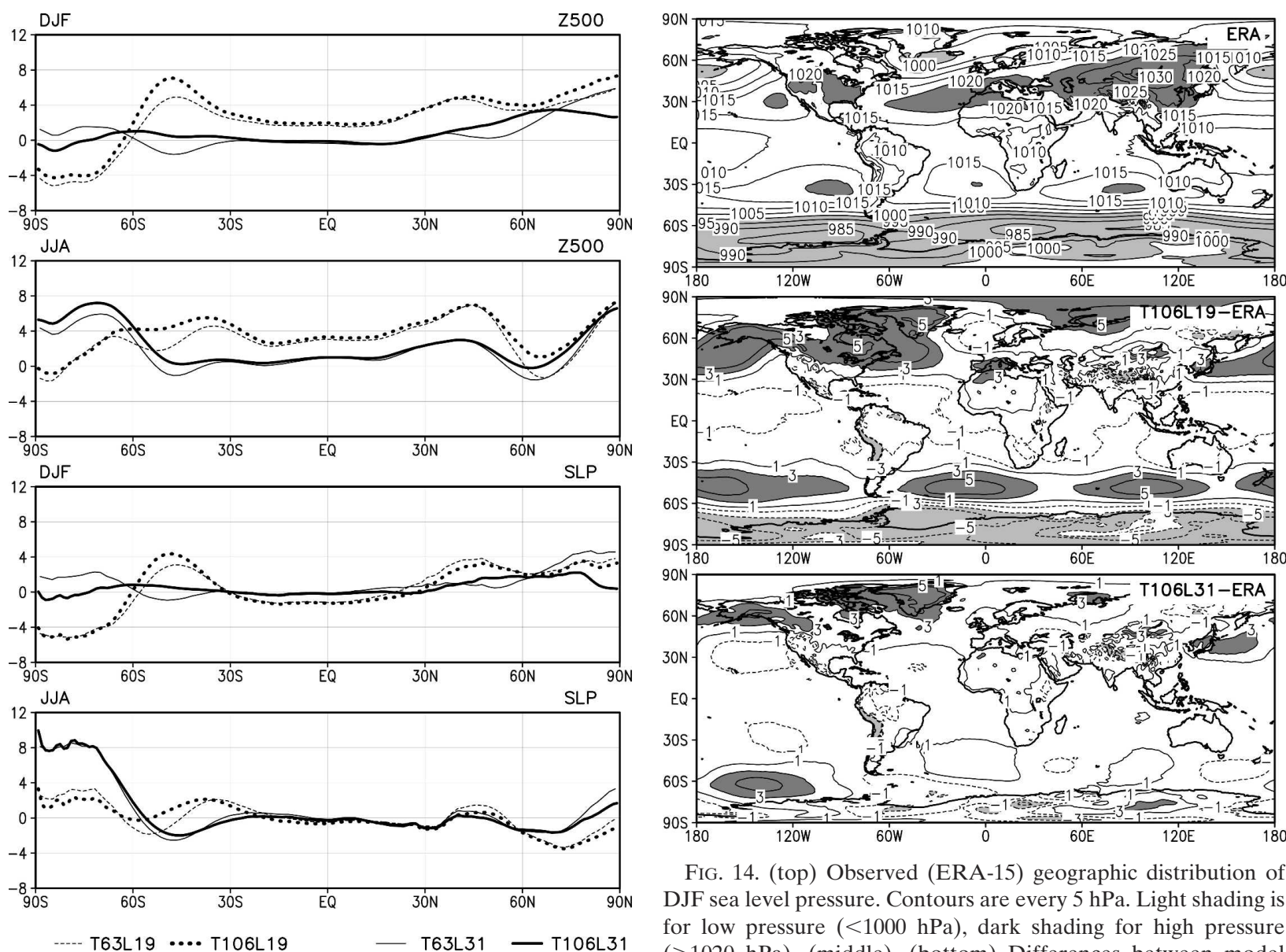

FIG. 13. Errors in DJF and JJA zonal mean 500-hPa geopotential height (Z500 in dam) and zonal mean sea level pressure (SLP in $\mathrm{hPa}$ ).

is considerably reduced by increasing the vertical resolution, especially in the T106L31 simulation.

\section{d. Water vapor and cloud}

The temperature differences between the L31 and L19 simulations (see Fig. 4) are associated with differences in specific and relative humidity, cloud cover, and cloud water content. Figure 18a shows the relative difference $(\%)$ of DJF specific humidity between the T106L31 and T106L19 simulations. A comparison with Fig. 4 indicates that some of the changes, but not all, may be directly linked with temperature changes. For example, the upper-tropospheric drying at lower latitudes and the moistening at high latitudes may be regarded as a response to the respective temperature changes, assuming that the changes in relative humidity are small. Although this assumption is approximately fulfilled in the polar lower and middle troposphere, the relative humidity below the tropical tropopause de-

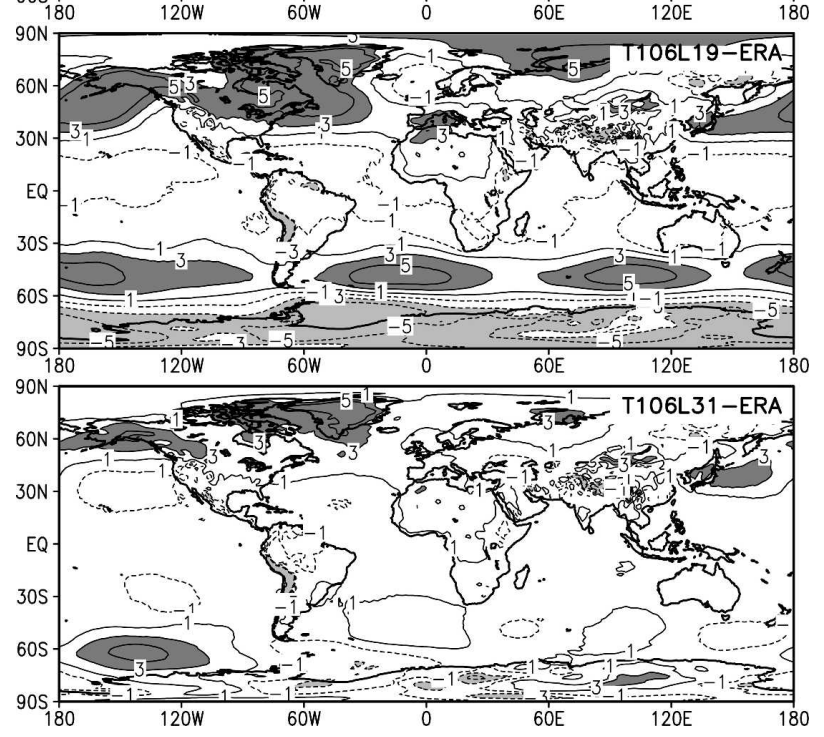

FIG. 14. (top) Observed (ERA-15) geographic distribution of DJF sea level pressure. Contours are every $5 \mathrm{hPa}$. Light shading is for low pressure $(<1000 \mathrm{hPa})$, dark shading for high pressure (>1020 hPa). (middle), (bottom) Differences between model simulations and ERA-15. Contours are $\pm 1,3,5$, and $10 \mathrm{hPa}$. Light shading is for low pressure biases in the simulations $(<-3 \mathrm{hPa})$, dark shading for high pressure biases $(>3 \mathrm{hPa})$.

creases actually by about $10 \%$ in the L31 simulations (not shown). The decrease in relative humidity is even larger in the polar upper troposphere and lower stratosphere, where the decline in specific humidity by up to $50 \%$ is accompanied by a warming of several degrees (Fig. 4). Here the drying is not simply a response to temperature changes. Very likely, the causality has to be reversed (M. Ponater 2004, personal commnication): In the previous model version, ECHAM4, the specific humidity around the 200-hPa level was up to 5 times higher compared to satellite data [the Halogen Occulation Experiment (HALOE)], whereas the model was spuriously dry by up to $50 \%$ in the polar lower stratosphere. By "nudging" the HALOE data into the ECHAM4 model, the cold polar bias was reduced by about $70 \%$ (i.e., by up to $8 \mathrm{~K}$ of its value in the control run). These results support the conclusion that the upper-tropospheric drying at higher vertical resolution is the main reason for the reduced cold polar bias in the L31 simulations. The differences (L31 - L19) in spe- 

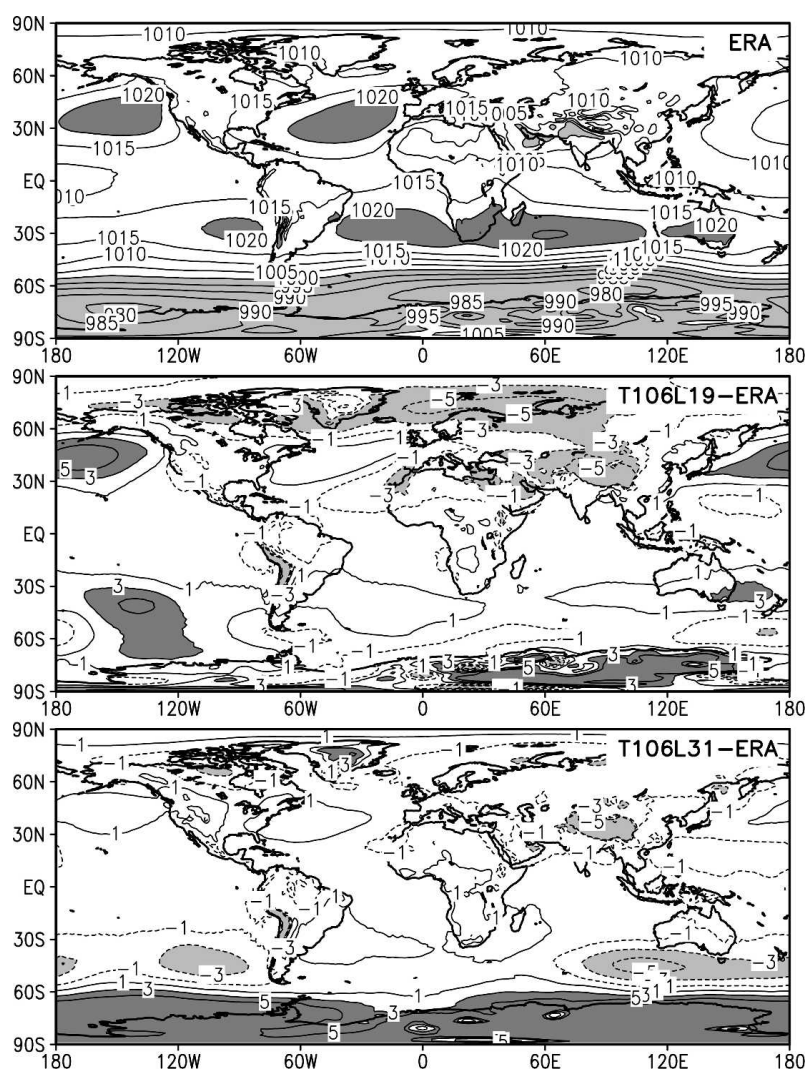

FIG. 15. As in Fig. 14, but for JJA

cific humidity and temperature are similar to those obtained by Pope et al. (2001), who found a dramatic improvement (i.e., a decrease) of upper-tropospheric humidity at higher vertical resolution (L30 compared to L19) and a decrease of the cold polar bias due to reduced longwave cooling at these levels. The decrease in specific humidity at higher vertical resolution can be related to a better representation of the polar tropopause and hygropause, which are spuriously shifted upward at lower vertical resolution. Numerical diffusion inherent in the transport algorithm for water vapor could be another contributing factor; that is, vertical humidity gradients can be better maintained at higher vertical resolution (see Figs. 18a,b, and also Fig. 10a of Pope et al. 2001). It is interesting to note that the cold polar bias can practically be eliminated by using a highly accurate, but computationally demanding, nondiffusive Lagrangian water vapor transport scheme (R. Sausen 2004, personal communication).

The differences (L31 - L19) at low latitudes are more complex because subgrid-scale processes like convection play a major role. Whereas the lower and middle troposphere are moister in the upward branch of the Hadley circulation, there is drying in the downward branches. These changes are consistent, with a slight strengthening of the Hadley circulation in the L31 simulations (not shown). Noteworthy is the local maximum of moistening around $600 \mathrm{hPa}$ for resolutions $\geq \mathrm{T} 63$. This is caused by a better representation of the melt layer. The extra cooling associated with snowmelt causes a marked change in stability so that deep convective clouds are not able to easily penetrate this layer, as in the L19 model, but start detraining in the melt layer already (Tompkins and Emanuel 2000; Inness et al. 2001). Analogously, the decrease in uppertropospheric humidity by typically $30 \%$ can partially be attributed to less frequent occurrence of deep convective clouds and the associated reduction of cloud-top detrainment. Although moistening by midtropospheric convective detrainment was also identified in HadAM3 L30 simulations (Pope et al. 2001; Inness et al. 2001), this was masked by other processes so that drying relative to L19 was simulated throughout the low-latitude troposphere. Part of the differences can be related to the horizontal resolution used in these studies (equivalent to T42). In fact, in our T42 simulation the moistening above $800 \mathrm{hPa}$ is very small. In addition to convective detrainment, the vertical humidity transport by the resolved scales is an important humidity source in the middle and upper troposphere. Insufficient vertical resolution could result in excessive numerical diffusion in the advection scheme. Therefore, the upper-tropospheric drying relative to L19 may be caused also by diminished vertical transport due to less artificial diffusion (Pope et al. 2001). The ECHAM5 and HadAM3 results agree qualitatively with those obtained in singlecolumn model studies by Tompkins and Emanuel (2000), who showed that convergence of humidity and temperature profiles in the Tropics can be achieved at a vertical resolution of about $25 \mathrm{hPa}$. At lower resolution (50 hPa), comparable to our L19, the humidity was spuriously high compared to the converged value by up to $30 \%$ in the upper half of the troposphere, and the temperature was also higher by up to $5 \mathrm{~K}$ than at 25 $\mathrm{hPa}$ resolution.

Most of the differences (L31 - L19) in DJF specific humidity can also be found in the JJA season (Fig. 18b). The largest decrease (by more than $50 \%$ for resolutions $\geq \mathrm{T} 63$ ) occurs over the summer pole, just above the 200-hPa level. Also, as in DJF, there is widespread drying in the upper troposphere and lower stratosphere, except for the region poleward of $60^{\circ} \mathrm{S}$, and a moistening (drying) in the upward (downward) branches of the Hadley circulation in the lower and middle troposphere. In JJA there is a larger hemispheric asymmetry than in DJF. In the Southern Hemisphere the moistening poleward of $30^{\circ} \mathrm{S}$ extends up to $400 \mathrm{hPa}$ and higher poleward of $60^{\circ} \mathrm{S}$. In the Northern Hemisphere the ex- 

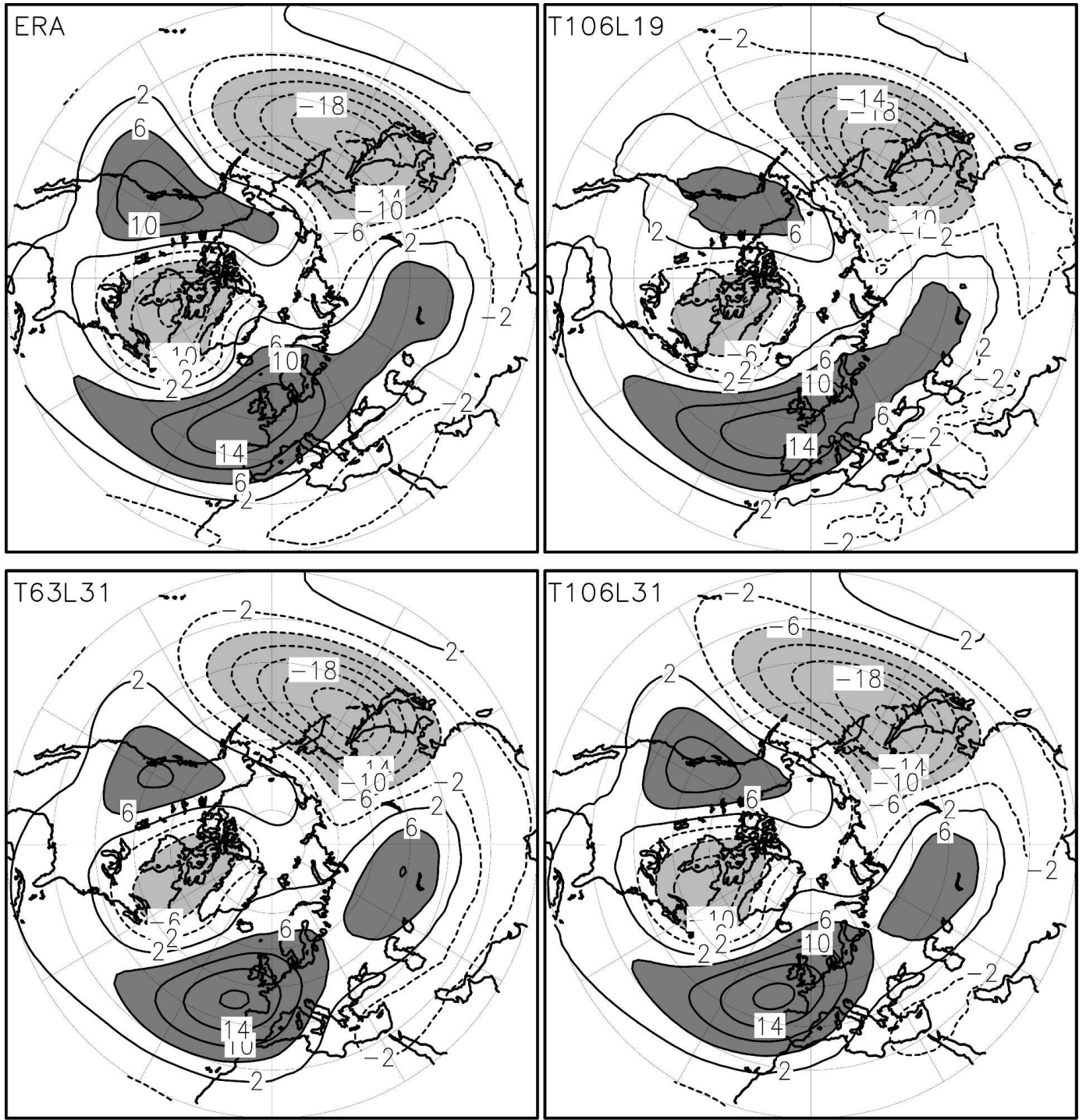

FIG. 16. Comparison of observed (ERA-15) and model-simulated DJF stationary wave patterns of 500-hPa geopotential height in the Northern Hemisphere. Contours are $\pm 2,6,10,14,18$, and 22 dam. Light shading is for height anomalies $<-6$ dam, dark shading for height anomalies $>6$ dam.

tratropical moistening is confined to the lower levels, especially at high horizontal resolution (T85, T106).

As for specific humidity, the differences (L31 - L19) in DJF and JJA cloud cover shown in Figs. 18c and 18d are largely independent of horizontal resolution. Cloud cover decreases by up to $10 \%$ in the upper levels but also in the boundary layer. Cloud cover increases predominantly in the midtroposphere with maxima of more than $3 \%$ at midlatitudes and in the upward branch of the Hadley circulation. Here, as for specific humidity (Figs. 18a,b), a local maximum in the snowmelt layer $(600 \mathrm{hPa})$ is generated. As to be expected, the differences in cloud cover are broadly consistent with those in cloud ice (Figs. 18e,f). The overall de- crease at higher levels and the increase below are indicative of a downward displacement of the tropopause at higher vertical resolution. In the Tropics this is related to changes in the frequency distribution of convective clouds; that is, midlevel detrainment is enhanced at the expense of high-level detrainment. In addition to the respective humidity changes (Figs. 18a,b), this contributes to a cooling relative to L19 (see Fig. 4) through enhanced cloud-top radiative cooling in the midtroposphere and reduced cloud radiative heating due to the decrease in high-level cirrus clouds. At high latitudes the decrease in cloud cover centered around $200 \mathrm{hPa}$ is consistent with that in humidity. Both changes contribute to the warming relative to L19 

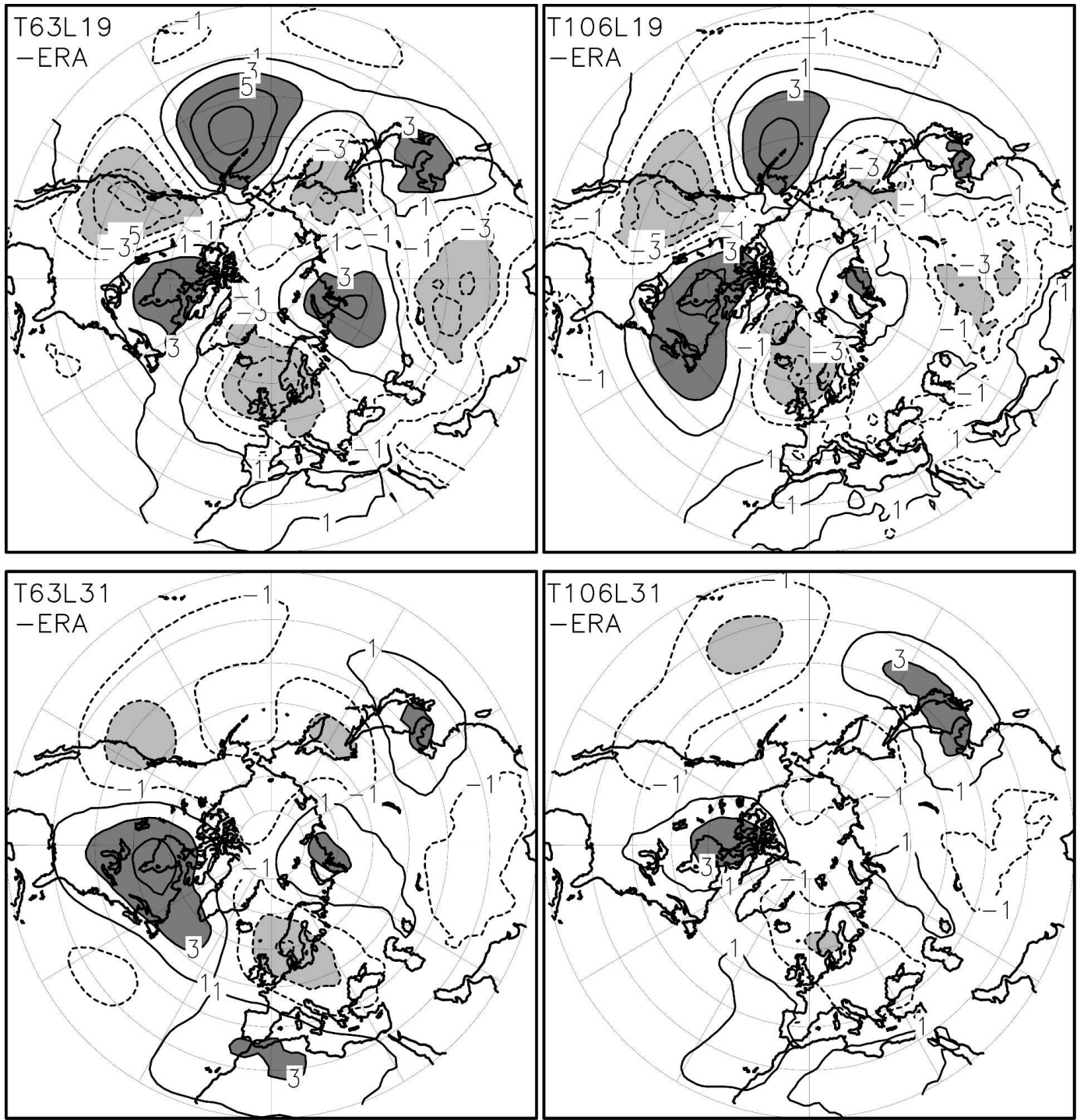

FIG. 17. As in Fig. 16, but for differences between model simulations and ERA-15. Contours are $\pm 1,3,5$, and 7 dam. Negative biases ( $<-3$ dam) are emphasized by light shading, positive biases ( $>3$ dam) by dark shading.

through a decrease in longwave radiative cooling at these levels. The L31 - L19 differences shown in Fig. 18 for the T106 simulations are not sensitive to the choice of the horizontal resolution: The broad-scale patterns are established already in the T42 simulations.

\section{Summary and concluding remarks}

As in many earlier studies (see section 1), increasing horizontal resolution leads to a warming of the troposphere, most prominently at midlatitudes, and, hence, to a poleward shift and intensification of the midlatitude westerlies. Increasing the vertical resolution has the opposite effect, almost independent of horizontal resolution: Whereas the atmosphere is colder at low and middle latitudes, it is warmer close to the surface and at high latitudes, most pronounced in the polar upper troposphere and lower stratosphere, where the cold polar bias is reduced by up to $50 \%$ compared to L19 simulations. Consistent with these temperature changes is a decrease and equatorward shift of the midlatitude westerlies. Higher vertical resolution also leads to a marked redistribution of humidity and clouds. Most notable is the drying of the upper troposphere (around the 200-hPa level) associated with a lowering of the tropopause and hygropause, which are spuriously shifted upward at lower vertical resolution because of the numerical diffusion inherent in the water vapor 

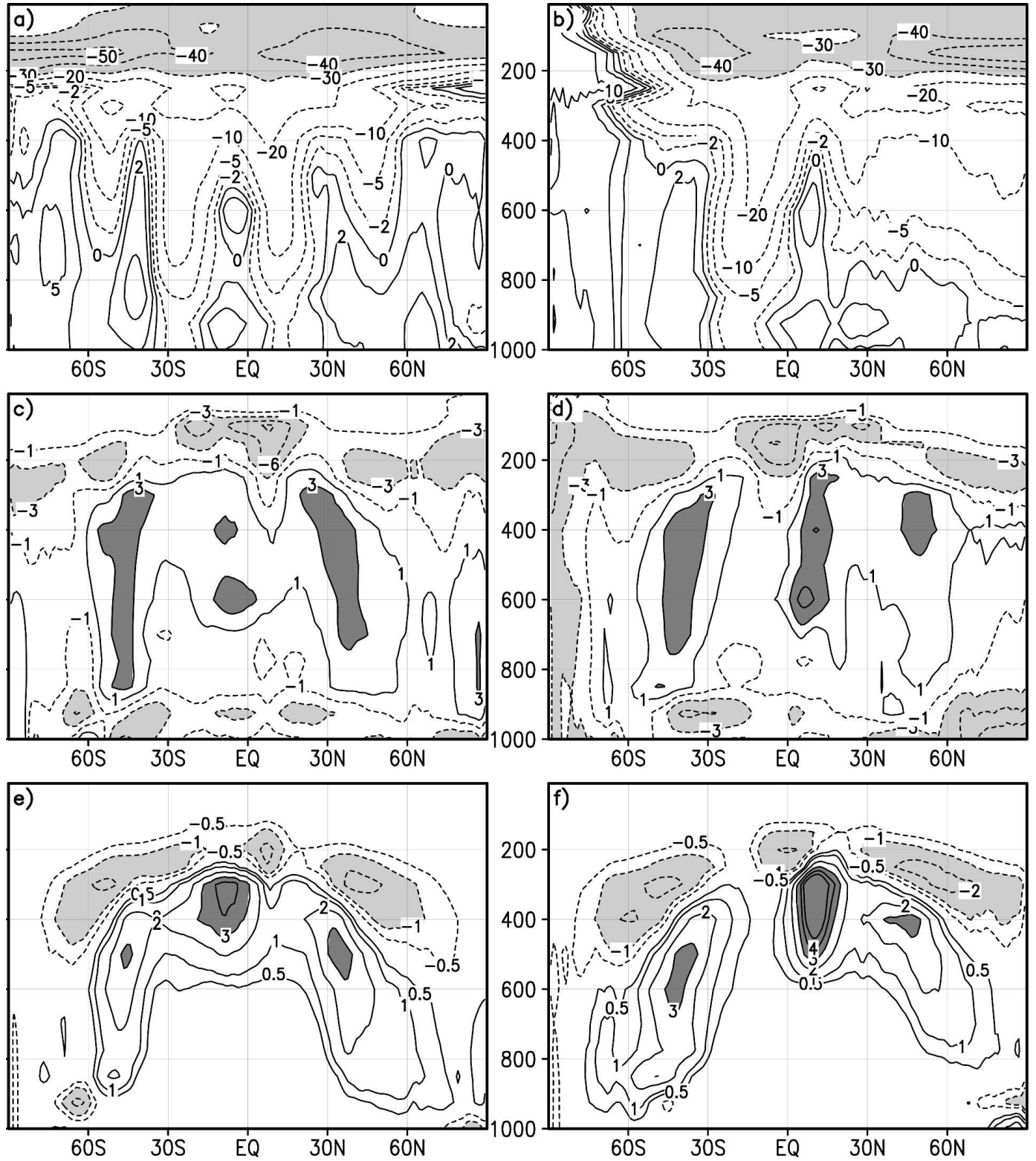

FIG. 18. Impact of vertical resolution (L31 vs L19) on zonal mean hydrologic variables in T106 model simulations for (left) DJF and (right) JJA. (a), (b) Relative differences (L31 - L19) $\times 100 /$ L19 in specific humidity. Contours are $-50 \%,-40 \%,-30 \%,-20 \%,-10 \%,-5 \%, 0 \%, 5 \%$, and $10 \%$. Light shading is for differences $<-30 \%$. (c), (d) Differences (L31 - L19) in cloud cover. Contours are $-9 \%,-6 \%,-3 \%,-1 \%, 1 \%, 3 \%$, and 6\%. Light shading is for differences $<-3 \%$, dark shading for differences $>3 \%$. (e), (f) Differences (L31 - L19) in cloud ice mixing ratio. Contours are $\pm 0.5,1,2,3,4$, and $5 \mathrm{mg} \mathrm{kg}^{-1}$. Light shading is for differences $<-1 \mathrm{mg} \mathrm{kg}^{-1}$, dark shading for differences $>3 \mathrm{mg} \mathrm{kg}^{-1}$.

transport algorithm. This problem is less severe at higher vertical resolution so that the vertical humidity gradients can better be maintained.

In the Tropics the humidity and cloud response to increased vertical resolution is related to changes in cloud-top detrainment of water vapor and cloud water/ ice. In agreement with Inness et al. (2001), enhanced vertical resolution leads to better representation of the snowmelt layer in the Tropics and, hence, to more frequent occurrence of cumulus clouds detraining at this level. This is reflected in the local increase of both humidity and clouds in our L31 simulations. Associated with a higher frequency of midtropospheric cumulus congestus is a lower frequency of deep cumulus clouds. The reduced convective detrainment contributes to the decline, relative to L19, of humidity and clouds in the 
tropical upper troposphere. The resulting upper-tropospheric cooling and drying, and also the moistening in the boundary layer and in the snowmelt layer, are qualitatively similar to the single-column model results obtained by Tompkins and Emanuel (2000), who stressed the need for sufficient vertical resolution (about $25 \mathrm{hPa}$ ) to correctly simulate the vertical profiles of humidity and temperature in the Tropics.

The answers to the questions raised in section $1 \mathrm{de}$ pend crucially on the vertical resolution used in the model. In the L19 simulations, as in most previous studies, there is little evidence for convergence to a more realistic climate state at horizontal resolutions $>$ T42. In the L31 simulations, on the other hand, the rmse decreases monotonically with increasing horizontal resolution (T42 to T159). Furthermore, except for T42 horizontal resolution, the L31 versions are superior to their L19 counterparts, and the improvements become more evident at increasingly higher horizontal resolutions. The substantial benefits in refining horizontal and vertical resolution at the same time give some support to scaling arguments deduced from quasigeostrophic theory (Lindzen and Fox-Rabinovitz 1989) implying that horizontal and vertical resolution ought to be chosen consistently.

In the past, increasing computer power has been used predominantly for increasing the horizontal resolution. According to our analyses, a more balanced choice of horizontal/vertical resolution not only improves the performance of the model but is beneficial also from an economic point of view. A striking example is the T106L19 model in comparison to T63L31. The latter is not only more efficient in terms of CPU time $(65 \%$ of T106L19) but also more accurate by more than $10 \%$ in terms of overall rmse. A further gain in quality by $10 \%$ can only be achieved at very high cost (factor of 13 with respect to T63L31 in the T159L31 model). Here the choice of resolution would be more subjective because the lack of accuracy in T63L31 can be balanced by the advantages of longer simulation length and larger ensembles.

Acknowledgments. The authors are grateful to JeanJacques Morcrette for providing the ECMWF version of the RRTM longwave radiation code, to Francois Lott, who made the SSO gravity wave drag scheme available to us, and to Burkhardt Rockel for deriving the cloud single-scattering properties from Mie calculations. The suggestions made by two anonymous reviewers substantially improved the quality of manuscript. The simulations were done on the NEC SX-6 at the German Climate Computing Center (DKRZ) in Hamburg.

\section{REFERENCES}

Boer, G. J., and B. Denis, 1997: Numerical convergence of the dynamics of a GCM. Climate Dyn., 13, 359-374.

Boyle, J. S., 1993: Sensitivity of dynamical quantities to horizontal resolution for a climate simulation using the ECMWF (cycle 33) model. J. Climate, 6, 796-815.

Branković, C., and D. Gregory, 2001: Impact of horizontal resolution on seasonal integrations. Climate Dyn., 18, 123-143.

Clough, S. A., F. X. Kneizys, and R. W. Davies, 1989: Line shape and the water vapor continuum. Atmos. Res., 23, 229-241.

Déqué, M., C. Dreverton, A. Braun, and D. Cariolle, 1994: The ARPEGE/IFS atmosphere model: A contribution to the French community climate modelling. Climate Dyn., 10, 249266.

Ebert, E. E., and J. A. Curry, 1992: A parameterization of cirrus cloud optical properties for climate models. J. Geophys. Res., 97, 3831-3836.

Fouquart, Y., and B. Bonnel, 1980: Computations of solar heating of the Earth's atmosphere: A new parameterization. Beitr. Phys. Atmos., 53, 35-62.

Gates, W. L., and Coauthors, 1999: An overview of the results of the Atmospheric Model Intercomparison Project (AMIP I). Bull. Amer. Meteor. Soc., 80, 29-55.

Gibson, J. K., P. Kallberg, S. Uppala, A. Hernandez, A. Nomura, and E. Serrano, 1997: ERA description. ECMWF Reanalysis Project Report Series, Vol. 1, European Centre for MediumRange Weather Forecasts, Reading, United Kingdom, 72 pp.

Hagemann, S., 2002: An improved land surface parameter dataset for global and regional climate models. Max Planck Institute for Meteorology Rep. 162, 21 pp. [Available from MPI for Meteorology, Bundesstr. 53, 20146 Hamburg, Germany.]

logical cycle in the ECHAM5 model. J. Climate, 19, 38103827.

Hartmann, D., 1993: Radiative effects of clouds on Earth's climate. Aerosol-Cloud-Climate Interactions, P. V. Hobbs, Ed., Academic Press, 151-173.

Inness, P. M., J. M. Slingo, S. J. Woolnough, R. B. Neale, and V. D. Pope, 2001: Organising of tropical convection in a GCM with varying vertical resolution: Implications for the simulation of the Madden-Julian Oscillation. Climate Dyn., 17, 777-793.

Lin, S. J., and R. B. Rood, 1996: Multidimensional flux-form semiLagrangian transport. Mon. Wea. Rev., 124, 2046-2068.

Lindzen, R. S., and M. S. Fox-Rabinovitz, 1989: Consistent vertical and horizontal resolution. Mon. Wea. Rev., 117, 25752583.

Lohmann, U., and E. Roeckner, 1996: Design and performance of a new cloud microphysics parameterization developed for the ECHAM4 general circulation model. Climate Dyn., 12, 557572.

Lott, F., and M. J. Miller, 1997: A new subgrid-scale orographic drag parameterization: Its formulation and testing. Quart. J. Roy. Meteor. Soc., 123, 101-127.

Mlawer, E. J., S. J. Taubman, P. D. Brown, M. J. Iacono, and S. A. Clough, 1997: Radiative transfer for inhomogeneous atmospheres: RRTM, a validated k-correlated model for the longwave. J. Geophys. Res., 102, 16 663-16 682.

Nordeng, T. E., 1994: Extended versions of the convective parameterization scheme at ECMWF and their impact on the mean and transient activity of the model in the tropics. European 
Centre for Medium-Range Weather Forecasts Tech. Memo. 206, 41 pp.

Pope, V. D., and R. A. Stratton, 2002: The processes governing horizontal resolution sensitivity in a climate model. Climate Dyn., 19, 211-236.

—, J. A. Pamment, D. R. Jackson, and A. Slingo, 2001: The representation of water vapor and its dependence on vertical resolution in the Hadley Centre climate model. J. Climate, 14, 3065-3085.

Raschke, E., A. Ohmura, W.B. Rossow, B.E. Carlson, Y.-C. Zhang, C. Stubenrauch, M. Kottek, and M. Wild, 2005: Cloud effects on the radiation budget based on ISCCP data (1991 to 1995). Int. J. Climatol., 25, 1103-1125.

Roeckner, E., and Coauthors, 2003: The atmospheric general circulation model ECHAM5. Part I: Model description. Max Planck Institute for Meteorology Rep. 349, 127 pp. [Available from MPI for Meteorology, Bundesstr. 53, 20146 Hamburg, Germany.]

Roesch, A., and E. Roeckner, 2006: Assessment of snow cover and surface albedo in the ECHAM5 general circulation model. J. Climate, 19, 3828-3843.

Stendel, M., and E. Roeckner, 1998: Impacts of horizontal resolution on simulated climate statistics in ECHAM4. Max Planck Institute for Meteorology Rep. 253, 57 pp. [Available from MPI for Meteorology, Bundesstr. 53, 20146 Hamburg, Germany.]

Stratton, R. A., 1999: A high resolution AMIP integration using the Hadley Centre model HadAM2b. Climate Dyn., 15, 9-28.

Tiedtke, M., 1989: A comprehensive mass flux scheme for cumulus parameterization in large-scale models. Mon. Wea. Rev., 117, 1779-1800.

Tompkins, A. M., 2002: A prognostic parameterization for the subgrid-scale variability of water vapor and clouds in largescale models and its use to diagnose cloud cover. J. Atmos. Sci., 59, 1917-1942.

_ and K. A. Emanuel, 2000: The vertical resolution sensitivity of simulated equilibrium temperature and water vapour profiles. Quart. J. Roy. Meteor. Soc., 126, 1219-1238.

Uppala, S. M., and Coauthors, 2005: The ERA-40 Re-analysis. Quart. J. Roy. Meteor. Soc., 131, 2961-3012.

Wild, M., and E. Roeckner, 2006: Radiative fluxes in the ECHAM5 general circulation model. J. Climate, 19, 37923809.

Williamson, D. L., 1999: Convergence of atmospheric simulations with increasing horizontal resolution and fixed forcing scales. Tellus, 51A, 663-673.

_ - J. T. Kiehl, and J. J. Hack, 1995: Climate sensitivity of the NCAR Community Climate Model (CCM2) to horizontal resolution. Climate Dyn., 11, 377-397. 